\title{
Estratégias de alinhamento para consulta cantarolada
}

\author{
Fábio Goródscy
}

\author{
DISSERTAÇÃO APRESENTADA \\ $\mathrm{AO}$ \\ Instituto DE MATEMÁticA E EstatísticA \\ DA \\ Universidade DE SÃo PAUlo \\ PARA \\ OBTENÇÃO DO TÍTULO \\ DE \\ Mestre em CiÊnCIAS \\ Programa: Ciência da Computação \\ Orientador: Prof. Dr. Marcelo Gomes de Queiroz
}

Durante o desenvolvimento deste trabalho o autor recebeu auxílio financeiro da CNPq

São Paulo, Agosto de 2019 
Estratégias de alinhamento para consulta cantarolada

Esta é a versão original da dissertação elaborada pelo candidato Fábio Goródscy, tal como submetida à Comissão Julgadora. 


\section{Agradecimentos}

Este trabalho não seria possível sem a ajuda de muitos, tanto na universidade como fora dela, ao longo de toda a trajetória deste trabalho, assim como antes dele ser iniciado. A todos que de alguma forma colaboraram, deixo aqui minha mais sincera gratidão. 


\section{Resumo}

GORÓDSCY, F. Estratégias de alinhamento para consulta cantarolada. 2018. 120 f. Dissertação (Mestrado) - Instituto de Matemática e Estatística, Universidade de São Paulo, São Paulo, 2018.

Consulta cantarolada é um tópico comum em recuperação de informação musical. Na tarefa de consulta cantarolada, uma gravação cantarolada, representando imprecisamente uma melodia de referência, é enviada para uma aplicação, que tem como objetivo recuperar a melodia de referência. Para realizar tal tarefa, um algoritmo precisa lidar com as diferenças entre a consulta e a melodia de referência, tanto no domínio do tempo quanto no domínio da frequência.

Neste trabalho revemos técnicas aplicadas em trabalhos comerciais e acadêmicos, em particular alguns algoritmos apresentados na conferência internacional de recuperação de informação musical (ISMIR), bem como a aplicação comercial Soundhound. Este trabalho compara resultados do desempenho das técnicas estudadas utilizando um amplo banco de dados aberto de consultas cantaroladas.

O objetivo principal deste trabalho é comparar estratégias de alinhamento, extração de características, rankeamento e processamentos para a tarefa de consulta cantarolada, destacando desafios, vantagens e qualidades de cada estratégia. Além disso, analisamos a confiabilidade de uma ferramenta comercial e comparamos seus resultados com os de outras abordagens.

Palavras-chave: Recuperação de informação musical, processamento de sinais, consulta cantarolada. 


\section{Abstract}

GORÓDSCY, F. Strategies for matching in Query-by-humming. 2018. 120 f. Dissertação (Mestrado) - Instituto de Matemática e Estatística, Universidade de São Paulo, São Paulo, 2018.

Query-by-humming is a common topic in music information retrieval. In the query-by-humming task a hummed record, representing imprecisely a target melody, is given to an application which is supposed to retrieve the target melody from a dataset. Any algorithm addressing this task has to handle the deviations between query and target melodies in both time and frequency domains.

This work reviews standard techniques presented in the academic literature and in commercial applications. Algorithms presented in the conference of the international society for music information retrieval (ISMIR) are reviewed, as well as the commercial application Soundhound, which are explored and tested. This work compares the performance of several strategies for query-byhumming within a unified query dataset.

The main goal of this work is to compare strategies of matching, feature exctration, ranking and processing for query-by-humming, highlighting qualities of each strategy. Also, the performance of a commercial tool is evaluated and compared to other approaches.

Keywords: Music information retrieval, signal processing, query-by-humming. 


\section{Sumário}

Lista de Abreviaturas $\quad$ xi

Lista de Figuras $\quad$ xiii

Lista de Tabelas $\quad$ xv

1 Introdução $\quad 1$

1.1 Motivação . . . . . . . . . . . . . . . . . . . . . . . . . 1

1.2 Trabalhos relacionados . . . . . . . . . . . . . . . . . . 1

1.2 .1 Soundhound . . . . . . . . . . . . . . . . . . . . . . 2

1.2 .2 Follow That Tune . . . . . . . . . . . . . . . . . . 2

1.2 .3 Tararira . . . . . . . . . . . . . . . . . . . . . 2

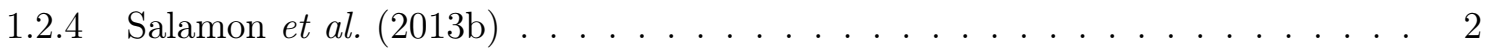

1.2 .5 Hum-a-song . . . . . . . . . . . . . . . . . . . . . . . . 2

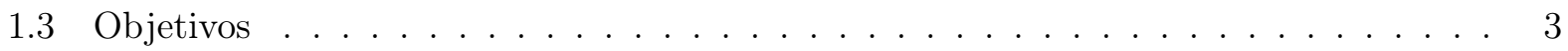

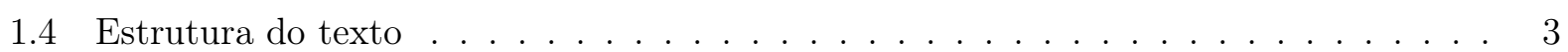

2 Conceitos $\quad 5$

2.1 Representações . . . . . . . . . . . . . . . . . . . . . . . . 5

2.1 .1 Áudio . . . . . . . . . . . . . . . . . . . 5

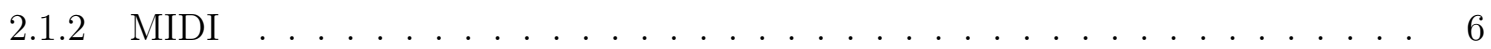

2.1.3 Frequência fundamental $\left(F_{0}\right) \ldots \ldots \ldots \ldots \ldots \ldots$

$2.1 .4 \quad$ Inter Onset Interval . . . . . . . . . . . . . . . . . . . . . . . . . . . . . . . . . 9

2.1 .5 Transcrição Áudio-MIDI . . . . . . . . . . . . . . . . . . . . . . . . . . . . 10

2.2 Alinhamento de subsequências . . . . . . . . . . . . . . . . . . . . . . . 11

2.2.1 Dynamic Time Warping (DTW) . . . . . . . . . . . . . . . . 12

2.2 .2 Alinhamento inexato . . . . . . . . . . . . . . . . . . . . . 14

2.3 Métricas de Avaliação . . . . . . . . . . . . . . . . . . . . . . . . . . . 16

$2.3 .1 \quad$ Precision e recall . . . . . . . . . . . . . . . . . . . . . . . . 17

2.3.2 Mean Reciprocal Rank (MRR) . . . . . . . . . . . . . . . . . . . . . 18

3 Metodologia $\quad 19$

3.1 Estrutura . . . . . . . . . . . . . . . . . . . . . . . . . 19

3.1 .1 Banco de dados . . . . . . . . . . . . . . . . . . . 19

3.1 .2 Métricas . . . . . . . . . . . . . . . . . . . 20

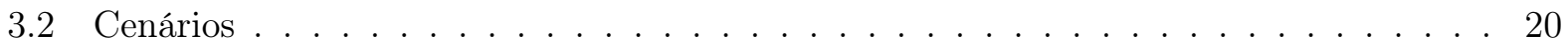


3.2.1 Avaliação de uma ferramenta existente . . . . . . . . . . . . . . . . . . . 21

3.2 .2 Sequências de alturas . . . . . . . . . . . . . . . . . . . . 21

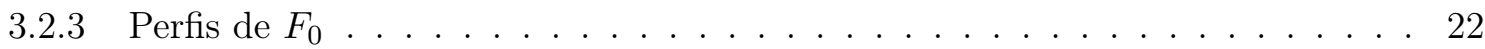

4 Experimentos e discussão $\quad 23$

4.1 Banco de dados . . . . . . . . . . . . . . . . . . . . . 23

4.2 Ferramenta existente: Soundhound . . . . . . . . . . . . . . . . . . 23

4.3 Recuperação via sequências melódicas (alturas e durações) . . . . . . . . . . . . . 27

4.4 Recuperação via perfis de F0 . . . . . . . . . . . . . . . . . . . . . . . . . . . 29

5 Conclusão $\quad 37$

Referências Bibliográficas $\quad 39$ 


\title{
Lista de Abreviaturas
}

\author{
QBH Busca com consulta cantarolada (Query By Humming) \\ DTW Dynamic Time Warping \\ MRR Mean Reciprocal Rank \\ IOI Inter Onset Interval \\ IOIR Inter Onset Interval Ratio \\ MIDI Musical Instrument Digital Interface \\ MIR Recuperação de informação musical (Musical Information Retrieval) \\ FFT Transformada rápida de Fourier (Fast Fourier Transform)
}




\section{Lista de Figuras}

1.1 Ilustração de aplicação de query-by-example musical . . . . . . . . . . . . . . . . 1

2.1 Um sinal de áudio contendo uma onda senoidal. O eixo horizontal representa o tempo, enquanto o vertical representa a pressão relativa do ar em um dado momento. . . . . 6

2.2260 amostras da gravação a $44100 \mathrm{~Hz}$ de uma nota E5 $(659.255 \mathrm{~Hz})$ no violão. A frequência fundamental corresponde a um período de $\frac{44100}{659.255} \approx 67$ amostras. . . . . . 7

2.3 Extração de $F_{0}$ com Melodia. . . . . . . . . . . . . . . . . . 8

2.4 Representações de alturas. . . . . . . . . . . . . . . . . . . . . . . . . . . 9

2.5 Representação de intervalos e durações. . . . . . . . . . . . . . . . . . . . . . . 10

2.6 Comparação entre representação MIDI e o perfil de alturas extraído do áudio. Em azul está a altura representada no arquivo MIDI, e em laranja está o resultado obtido com gravação cantarolada. . . . . . . . . . . . . . . . . . . . . 11

2.7 Transcrição de áudio para MIDI. Em laranja está o conteúdo do arquivo MIDI de referência. Em azul está o resultado da transcrição a partir do áudio. . . . . . . . . . . 11

2.8 Matriz D quando produzida a partir de uma música comparada a si mesma. . . . . . 13

2.9 Exemplo de caminhos com seus custos acumulados. Vemos que a figura da direita teve um custo menor. . . . . . . . . . . . . . . . . . . . . . . . . . 13

3.1 Fluxos do processamento para uma consulta cantarolada. . . . . . . . . . . . . . . . 19

3.2 Relação entre identificador e melodias/consultas. . . . . . . . . . . . . . . . . . . . 20

3.3 A ferramenta de busca cantarolada recebe uma consulta e retorna uma lista de res-

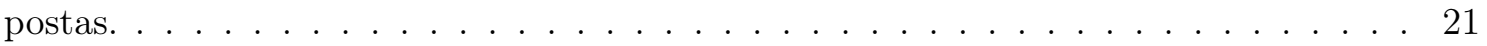

3.4 O alinhamento é feito entre a transcrição da consulta e as representações simbólicas das melodias. . . . . . . . . . . . . . . . . . . . . . 22

3.5 O alinhamento é feito com a representação vetorial da consulta e as representações vetoriais das outras consultas armazenadas no banco. . . . . . . . . . . . . . . . 22

4.1 Processo de execução do experimento. . . . . . . . . . . . . . . . . . . . . . . 24

4.2 Trecho das melodias 1 - Alouette (azul) e 43 - Itsy bitsy spider (laranja) em sequências de classes de alturas. . . . . . . . . . . . . . . . . . . . 26

4.3 Algoritmo de transcrição que utiliza o Melodia. . . . . . . . . . . . . . . . . . . . 29

4.4 Passos de processamento neste experimento. . . . . . . . . . . . . . . . . 31 


\section{Lista de Tabelas}

2.1 Lista de eventos midi. . . . . . . . . . . . . . . . . . . . . . 6

2.2 Ilustração de matriz D considerando $X \in \mathbb{R}^{5}, Y \in \mathbb{R}^{6}, X=(4,10,2,3,5), Y=$

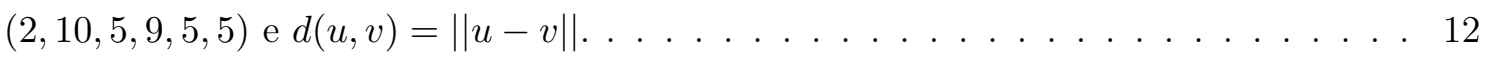

2.3 Ilustração da computação de C . . . . . . . . . . . . . . . . . . . . . 15

2.4 Ilustração da computação de $\mathrm{C}$, com $f\left(x_{n}\right)=0$, considerando $X=(4,10,2,3,5)$ e

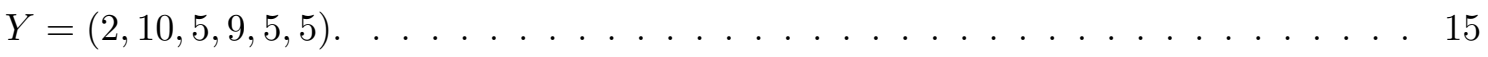

2.5 Ilustração da computação de C. $f\left(x_{n}\right)=0.5 x_{n}, \alpha=2, \beta=1 \ldots \ldots \ldots$

2.6 Conjuntos usados nas definições de precision e recall $\ldots \ldots \ldots$. . . . . . . . . 17

4.1 Lista dos títulos encontrados pelo Soundhound, com o respectivo identificador utilizado para a melodia no banco de dados do MIREX. . . . . . . . . . . . . . 25

4.2 Lista de resultados do Soundhound para consultas referentes à melodia 1 - Alouette . 26

4.3 Lista geral de resultados do Soundhound, agrupados por melodia . . . . . . . . . . 27

4.4 Resultados para as buscas usando sequências melódicas, em função do sistema de transcrição (ASyMuT e Melodia), técnica de alinhamento (SMBGT e DTW) e representação (intervalos de alturas e onsets) . . . . . . . . . . . . . . 30

4.5 Resultado da alteração dos parâmetros no algoritmo de transcrição. . . . . . . . . . . . 30

4.6 Valores para diferentes melhorias utilizando as consultas da melodia 1. . . . . . . . 32

4.7 Resultados de RR, MRR, Recall e posição média para diferentes formas de ranking utilizando as consultas da melodia 1. . . . . . . . . . . . . . . . . 33

4.8 Valores para classificação consulta $\times$ consulta, considerando o ranking criado com o resultado dos alinhamentos. . . . . . . . . . . . . . . . . 34

4.9 Valores gerais de MRR e recall em função do modelo de ranking. . . . . . . . . . . . . 35

5.1 Lista geral de resultados agrupados por melodia . . . . . . . . . . . . . . . 38 


\section{Capítulo 1}

\section{Introdução}

\subsection{Motivação}

A conexão com a internet alterou a forma como realizamos pesquisas no computador, já que os dados de busca não precisavam mais estar no nosso computador pessoal, mas poderiam estar em qualquer local na web. Hoje em dia o query-by-example vem também alterando a realização de buscas, que desde o princípio era realizada apenas através de informações textuais. É possível traduzir um texto fotografado, identificar um objeto pela sua imagem e reconhecer uma música através de seu som (figura 1.1). Porém, a consulta de uma melodia cantarolada (query-by-humming, ou QBH) em recuperação de informação musical (music information retrieval, ou MIR) segue sendo um desafio. Além de possíveis aplicações comerciais (em serviços de streaming), essa tarefa também pode ser abordada de forma figurativa, como uma maneira de entender diversos outros problemas e dificuldades relacionados com o processamento de sinais musicais, a busca em grandes bancos de dados e questões relacionadas à percepção musical humana.

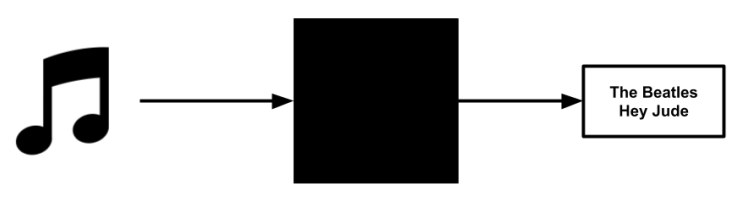

Figura 1.1: Ilustração de aplicação de query-by-example musical

A expectativa do usuário ao utilizar uma ferramenta de QBH é, ao enviar uma reprodução vocal bem intencionada da melodia que tem em mente, obter informações sobre possíveis títulos, intérpretes, versões, locais ou outros dados que o ajudem a encontrar músicas com aquela melodia. O usuário é capaz de tolerar quando a resposta esperada não é encontrada, mas se as respostas não conseguem remeter em nada à consulta, o usuário pode perder a confiança na ferramenta, questionando seu funcionamento.

\subsection{Trabalhos relacionados}

Nesta seção iremos descrever alguns trabalhos de QBH. Vale citar que existem trabalhos de query-by-example muito importantes no contexto musical, mas que serão omitidos por serem menos relevantes para o conteúdo deste trabalho. Dentre esses, temos os trabalhos de audio fingerprinting, que tratam da busca exata de gravações consultadas, como aquela realizada pelo aplicativo Shazam (Wang, 2003), e o framework Echoprint (Ellis et al., 2011). 


\subsubsection{Soundhound}

O Soundhound é uma plataforma aberta de query-by-example musical, a qual, diferentemente do Shazam, permite realizar QBH. O Soundhound, antes conhecido como Midomi (Wikipedia, 2019), utiliza a estratégia de alinhamento de consulta contra consulta (MIREX, 2017). Isso quer dizer que o Soundhound possui uma lista de gravações cantaroladas, classificadas de acordo com a melodia que elas representam, e utiliza essa base para gerar um ranking e tentar classificar novas consultas cantaroladas realizadas. Ele ainda possui uma interface web através do Midomi, mas sua interface principal hoje se dá através dos aplicativos que podem ser baixados gratuitamente em dispositivos com Android e IOS. As consultas são gravadas através do microfone do dispositivo e enviadas ao servidor da ferramenta, que irá alinhar a consulta com a base de dados no servidor. Caso encontre algo similar, o servidor devolve ou uma resposta identificada ou uma lista de possíveis respostas, sendo que cada resposta possui uma página com informações complementares, como título, artista e vídeos associados.

\subsubsection{Follow That Tune}

O Follow That Tune (Stasiak, 2014) foi apresentado na competição anual de QBH do MIREX ${ }^{1}$ (Music Information Retrieval Evaluation eXchange), um evento satélite da confêrencia do ISMIR ${ }^{2}$ (International Society for Music Information Retrieval), a mais importante para a área de MIR. Este trabalho utiliza contornos melódicos para realizar o alinhamento, e tem como foco o problema do alinhamento no caso do canto estar em um tom diferente do que está no template, que é a versão que está no banco de dados. A solução explorada no artigo é um modelo iterativo que aproxima gradualmente o tom da consulta do tom do template. O código não está disponível.

\subsubsection{Tararira}

O Tararira (López et al., 2004) propõe um método de combinação entre busca sobre contornos melódicos e comparação de transcrições simbólicas. Esta aplicação foi desenvolvida para desktops Linux e o código fonte está disponível online ${ }^{3}$. Apesar de disponível, a aplicação foi desenvolvida em 2004 e hoje, em 2019, a compilação não pode ser feita diretamente, mesmo em plataforma Linux 32 bits, a mesma em que foi desenvolvido, sendo necessário muitos ajustes para reproduzir a aplicação. O Tararira foi utilizado em Costa (2015), onde um banco de consultas especificamente criado para os experimentos (e que não foi disponibilizado) é alinhado através do Tararira com transcrições MIDI extraídas de arquivos de músicas gravadas em estúdio. O código utilizado para esses experimentos também não está disponível.

\subsubsection{Salamon et al. (2013b)}

Neste trabalho, um algoritmo é proposto para criar representações melódicas que serão utilizadas para algoritmos de identificação de versões de músicas. Nele, o mesmo algoritmo é testado também para a tarefa de QBH. Eles utilizam um banco de consultas pequeno ${ }^{4}$, com 118 gravações. Como base de conhecimento, eles utilizam 481 gravações originais em áudio e transcrevem para a mesma representação utilizada para as consultas. Para o alinhamento eles utilizam o algoritmo descrito em Serrà et al. (2009).

\subsubsection{Hum-a-song}

Esta aplicação aparece em Kotsifakos et al. (2012), e utiliza o algoritmo de alinhamento Subsequence Matching with Gaps-Range-Tolerances (SMBGT) (Kotsifakos et al., 2011). O algoritmo

\footnotetext{
${ }^{1}$ https://www.music-ir.org/mirex/wiki/MIREX_HOME

${ }^{2}$ https://ismir.net

${ }^{3}$ https://iie.fing.edu.uy/investigacion/grupos/gmm/proyectos/tararira/descargas/tarariraES-src-0.1.tar.gz

${ }^{4}$ http://mtg.upf.edu/download/datasets/MTG-QBH
} 
alinha representações simbólicas com transcrições de consultas. A aplicação foi desenvolvida utilizando Matlab e, na página ${ }^{5}$, o autor informa que disponibiliza o código, mas não obtivemos acesso.

\subsection{Objetivos}

Neste trabalho, levantaremos questões sobre descritores de áudio, algoritmos de alinhamento e ferramentas a serem utilizadas na tarefa de QBH. As questões que iremos discutir ao longo deste trabalho são:

- As respostas retornadas por ferramentas existentes que realizam consultas cantaroladas são respostas corretas ou, pelo menos, razoáveis?

- Uma representação exclusivamente melódica criada a partir de uma representação simbólica encontra respostas corretas ao ser alinhada no processo de consulta cantarolada?

- Uma representação exclusivamente rítmica criada a partir de uma representação simbólica encontra respostas corretas ao ser alinhada no processo de consulta cantarolada?

- A representação gerada por um algoritmo de transcrição afeta os resultados de buscas que o utilizam? Entre um conjunto de ferramentas a ser estudado, existe alguma ferramenta de transcrição que gera resultados corretos mais frequentemente que outras?

- Um algoritmo que alinha descritores gerados a partir de consultas com descritores de outras consultas pré-classificadas retorna respostas corretas?

Através da análise dessas questões, esperamos chegar em conclusões sobre técnicas, descritores e algoritmos razoáveis para executar a tarefa de QBH.

\subsection{Estrutura do texto}

Nos próximos capítulos discutiremos os conceitos necessários para compreensão de trabalhos que envolvem processamento de áudio, alinhamento de sequências e avaliação de resultados (capítulo 2); as metodologias utilizadas para definição de experimentos de consulta cantarolada (capítulo 3); descreveremos os experimentos realizados e seus resultados (capítulo 4); e, por fim, discutiremos o resultado final do trabalho, pontos de aprendizado e possibilidades de trabalhos futuros (capítulo 5). Espera-se que esse trabalho contribua com uma visão geral da área de QBH, principalmente exibindo um painel sobre uma ferramenta já existente e opções de abordagens, mostrando o esforço necessário para a obtenção de resultados razoáveis, a fim de permitir o desenvolvimento de novos trabalhos e novas ideias sobre o tema.

\footnotetext{
${ }^{5}$ http://vlm1.uta.edu/ akotsif/hum-a-song/
} 


\section{Capítulo 2}

\section{Conceitos}

O foco deste capítulo é apresentar conceitos fundamentais que são utilizados ao longo deste trabalho. A seção 2.1 trata de representações digitais que são comumente utilizadas para armazenar informação de músicas. Na seção 2.2 são apresentadas técnicas para alinhamento que podem ser aplicadas nestas representações digitais, com o intuito de verificar quão próximas são 2 representações, ou quão custoso é transformar uma na outra. Por fim, a seção 2.3 lista métricas para avaliação dos resultados.

\subsection{Representações}

Nesta seção são discutidas algumas representações utilizadas para dados de música. Todas as representações apresentadas são amplamente discutidas na literatura (Collins, 2010; Moore, 1990; Müller, 2015; Roads et al., 1996) e portanto será feita apenas uma discussão breve para esclarecer a forma como a representação será usada neste trabalho. Na seção 2.1.1 será comentado sobre sinais de áudio e sobre o processo de extração de descritores. A seção 2.1.2 traz um exemplo do que se denomina representação simbólica usando instruções MIDI. A seção 2.1.3 descreve a frequência fundamental como descritor de áudio e algoritmos de obtenção automática deste descritor. A seção 2.1.4 apresenta o descritor rítmico conhecido como Inter Onset Interval. A seção 2.1.5 discute a possibilidade de aproximar um sinal de áudio por uma representação simbólica.

\subsection{1 Áudio}

Ondas sonoras são funções da variação da pressão do ar em relação ao tempo, e sinais de áudio uma possível representação de tais funções. A figura 2.1 mostra um exemplo de sinal de áudio. Quando lidamos com o domínio digital, um sinal de áudio é uma sequência de números $Y=\left(y_{0}, y_{1}, \ldots, y_{N-2}, y_{N-1}\right), N \in \mathbb{N}$, onde cada elemento da sequência é associado à amplitude do sinal em um dado momento. A taxa de amostragem define a relação entre o índice das amostras e o tempo em segundos, restringindo também o tipo de onda que pode ser representada (ao definir a mais rápida oscilação que pode ser armazenada).

Sinais de áudio podem ser reproduzidos e representarão de forma precisa o ambiente sonoro num ponto de captação. Dependendo da forma como foi gravado, o sinal de áudio não acrescentará distorção perceptível para um ouvinte. Nesse sentido, o sinal de áudio cumpre perfeitamente sua função. Porém, para análise automática do conteúdo do áudio, será necessário obter características, ou descritores do sinal que possam ajudar na tarefa a ser realizada.

A transformada de Fourier pode ser utilizada para representar ondas sonoras como combinações de componentes senoidais, como a onda senoidal vista na figura 2.1. A decomposição realizada por esse processo se aproxima da forma como nosso ouvido reage a informações sonoras complexas. Com esse processo pode-se descobrir características melódicas presentes no áudio, como, por exemplo, o vetor de frequências fundamentais. Em um contexto digital, a transformada de Fourier consegue aproximar as componentes senoidais presentes na gravação, mas há um limite de resolução de tempo 


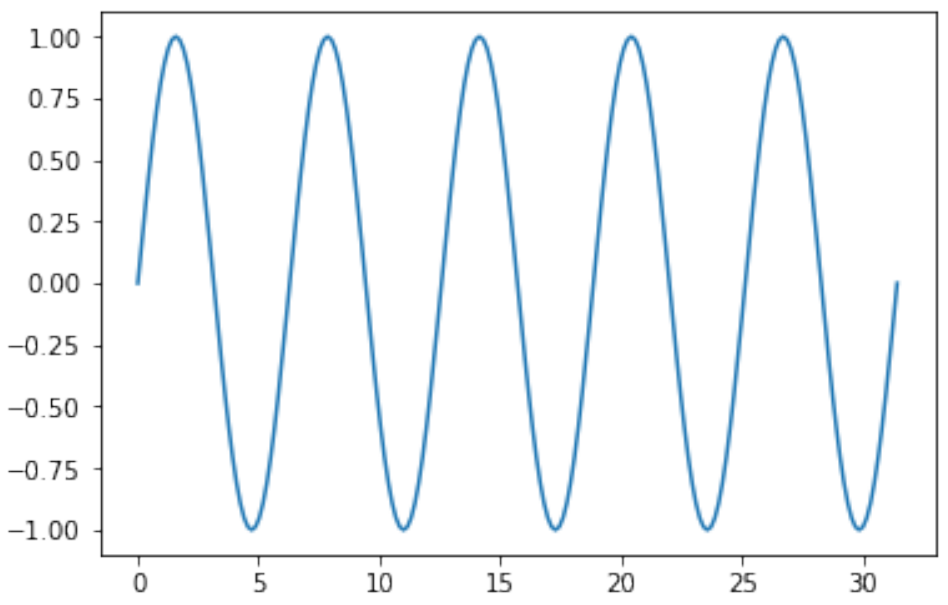

Figura 2.1: Um sinal de áudio contendo uma onda senoidal. O eixo horizontal representa o tempo, enquanto o vertical representa a pressão relativa do ar em um dado momento.

e frequência, sendo que quanto melhor a resolução em tempo, menor a resolução em frequência. Limitações como essa podem causar imprecisão na extração de características do áudio.

\subsubsection{MIDI}

O protocolo MIDI foi originalmente desenhado como padrão de comunicação para instrumentos musicais digitais, mas acabou se tornando popular como uma forma de representação simbólica. Apesar das diversas limitações que impõe, existe um grande número de obras transcritas em formato MIDI e livremente disponíveis na web. Um arquivo MIDI é composto por eventos que traduzem, por exemplo, o apertar de uma tecla: para tal, o evento deve armazenar informações como o número da tecla apertada e a intensidade com que a tecla foi apertada. Esses eventos podem ser armazenados em uma lista com informação temporal correspondente, e assim podem ser posteriormente utilizados para controlar um dispositivo de síntese. Um exemplo de lista de eventos pode ser vista na tabela 2.1. Os campos importantes para este trabalho em um evento MIDI são o início de evento, o tipo de evento, a altura e a intensidade. Um evento Note_on_c indica que o evento começou no tempo correspondente e com a intensidade informada. O Note_off_c desliga um evento que estava sendo executado. O campo altura é um número inteiro entre 0 e 127, que por padrão se traduz nas alturas de C-1 a G9 em notação científica de pitch ${ }^{1}$; em particular, esse parâmetro não permite representar alturas fracionárias, associadas a frequências que caem fora da escala do temperamento igual.

$\begin{array}{cccccc}\text { Faixa } & \text { Início } & \text { Tipo } & \text { Canal } & \text { Altura } & \text { Intensidade } \\ 1 & 0 & \text { Note_on_c } & 0 & 60 & 100 \\ 1 & 15 & \text { Note_off_c } & 0 & 60 & 0 \\ 1 & 15 & \text { Note_on_c } & 0 & 55 & 100 \\ 1 & 20 & \text { Note_off_c } & 0 & 55 & 0 \\ 1 & 20 & \text { Note_on_c } & 0 & 57 & 100 \\ 1 & 25 & \text { Note_off_c } & 0 & 57 & 0\end{array}$

Tabela 2.1: Lista de eventos midi.

Listas de eventos MIDI conseguem representar peças musicais com informações suficientes para serem compreendidas e executadas. Enquanto a informação melódica precisa ser extraída algoritmicamente do áudio, ela pode ser obtida diretamente do MIDI. Além disso, uma lista MIDI consegue

\footnotetext{
${ }^{1}$ https://en.wikipedia.org/wiki/Scientific_pitch_notation. Acessado em 17/08/2019.
} 
ser armazenada em espaço muitas ordens de grandeza menor, quando comparado com a representação em áudio.

\subsubsection{Frequência fundamental $\left(F_{0}\right)$}

Alguns sinais de áudio podem ser descritos como uma combinação de componentes senoidais com frequências múltiplas inteiras de uma mesma frequência fundamental (o que se denomina série harmônica), caracterizando um sinal periódico como na figura 2.2. O mecanismo de produção da voz humana produz séries harmônicas, assim como diversos instrumentos musicais. É comum associar esses sons à sua frequência fundamental $F_{0}$, que é aquela que repete seu padrão de forma de onda mais lentamente, ou seja, a componente mais grave da série harmônica.

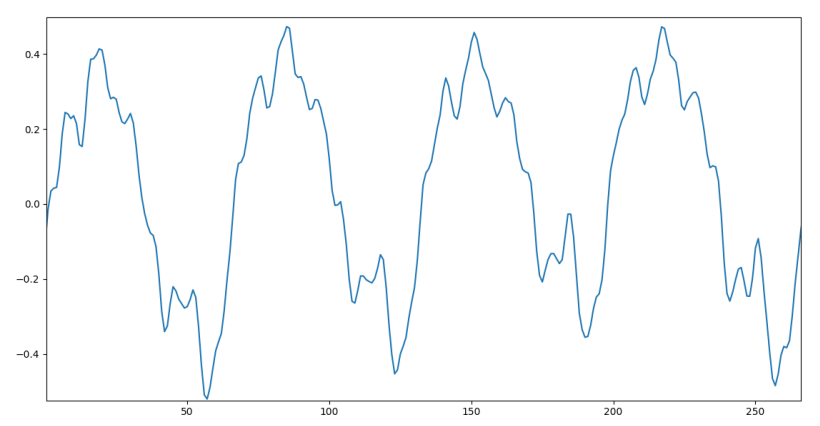

Figura 2.2: 260 amostras da gravação a $44100 \mathrm{~Hz}$ de uma nota E5 (659.255 Hz) no violão. A frequência fundamental corresponde a um periodo de $\frac{44100}{659.255} \approx 67$ amostras.

A relação entre frequência fundamental e altura musical ou pitch é complexa, visto que a altura é um produto da percepção humana e seu estudo pertence à área da psicoacústica. Simplificadamente, pode-se estabelecer uma relação objetiva entre essas duas representações através de uma expressões matemáticas que levem de uma escala linear para uma logarítmica.

\section{Classes de altura}

Notas $^{2}$ que tenham frequências fundamentais relacionadas através de potências de 2 são percebidas de forma muito similar, o que faz com que tais notas sejam perceptualmente agrupadas em uma mesma classe de altura. Por exemplo, dois sons harmônicos com frequências fundamentais $F_{0}$ de $110 \mathrm{~Hz}$ e $220 \mathrm{~Hz}$, respectivamente, são percebidos como se correspondessem ao mesmo pitch, exceto por uma diferença de uma oitava ${ }^{3}$. Na escala temperada de 12 semitons iguais, as classes de alturas correspondem a $C, C \sharp=D b, D, D \sharp=E b, E, F, F \sharp=G b, G, G \sharp=A b, A, A \sharp=B b, B$ e são representados frequentemente pelos valores inteiros $0,1, \ldots, 11$.

\section{Extração de $F_{0}$}

O processo de extração de $F_{0}$ é definido como, a partir de um sinal de áudio segmentado em $N$ trechos indexados por $k=0,1, \ldots, N-1$, obter uma sequência $F=\left(f_{0}, f_{1}, \ldots, f_{N-2}, f_{N-1}\right), N \in \mathbb{N}$, onde cada elemento $f_{k}$ é a estimativa de $F_{0}$ no $k$-ésimo trecho da gravação. A partir de $F$ é trivial obter uma sequência correspondente de classes de altura $P=\left(p_{0}, p_{1}, \ldots, p_{N-2}, p_{N-1}\right)$ a partir da equação para $F_{0}(p)$.

\footnotetext{
${ }^{2} \mathrm{O}$ termo "nota" é muito frequentemente usado em música para designar um evento sonoro com altura musical definida, que pode ser representado simplificadamente através de 4 parâmetros principais: altura musical e/ou frequência fundamental, intensidade e/ou amplitude, duração e nome do instrumento musical utilizado na produção do evento.

${ }^{3} \mathrm{O}$ nome dado ao intervalo musical entre duas frequências da forma $F$ e $2 \times F$, ou equivalentemente, à razão entre frequências $2: 1$.
} 


\section{ASyMuT}

Em (Mitre e Queiroz, 2005), submúltiplos da frequência com maior energia no espectro de magnitude são candidatos a $F_{0}$ e uma função de proeminência é descrita para seleção do valor de $F_{0}$. Para tal, um espectrograma é calculado sobre o sinal a ser analisado, com tamanho de janela e hop size definidos pelo usuário. Para cada quadro do espectrograma, picos de máximo local são encontrados para determinar possíveis parciais. $\mathrm{O}$ candidato natural para $F_{0}$ é o parcial de maior amplitude $f_{*}$. Depois, um conjunto de outros candidatos a $F_{0}$ é definido por

$$
F=\left(\frac{f_{*}}{1}, \frac{f_{*}}{2}, \ldots, \frac{f_{*}}{N-1}, \frac{f_{*}}{N}\right), N \in \mathbb{N},
$$

sendo que $\mathrm{N}$ define a menor frequência de $F_{0}$ detectável. É definido um vetor $H[n][i]$ então, que contém a frequência e a magnitude do harmônico i para o n-ésimo candidato a $F_{0}$. A função de proeminência é definida como

$$
P(n)=\sum_{i=1}^{I} H[n][i]_{m a g} * \Psi(i),
$$

onde $\Psi(i)$ é um fator de ponderação que decresce com i. São selecionados os candidatos com $\mathrm{P}(\mathrm{n})$ acima de um limiar e, dentre esses, é escolhido aquele que maximiza a expressão

$$
\chi(n)=\frac{P(n)}{\sum_{i=1}^{I} \Psi(i)} .
$$

Esse algoritmo é usado no ASyMuT (Automatic System for Music Transcription) e, apesar de estarmos descrevendo aqui apenas o método para extração de frequência fundamental, ele é também um sistema completo de transcrição para MIDI, como veremos mais adiante, na seção 2.1.5.

\section{Melodia}

Em Melodia (Salamon e Gómez, 2012), é realizada a localização de picos em janelas de espectro e candidatos de $F_{0}$ recebem valores de saliência de forma bastante semelhante ao ASyMuT. O passo de seleção de $F_{0}$ em cada quadro, porém, envolve rastreamento de contornos melódicos, o que significa que o algoritmo considera a evolução do $F_{0}$ no tempo para definir se há realmente um instrumento harmônico no sinal. Na figura 2.3 vemos o resultado da extração de $F_{0}$ com o Melodia, já convertido para notação MIDI.

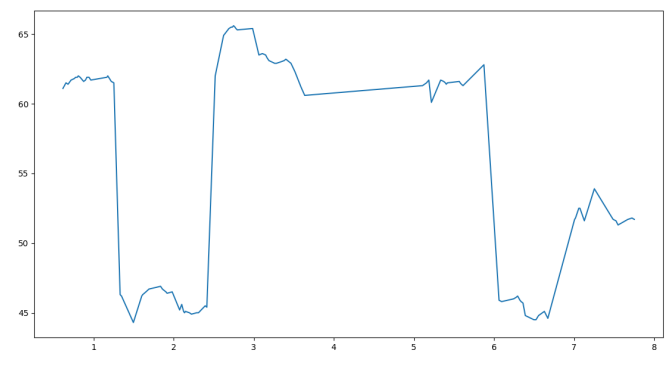

(a) Perfil de altura em MIDI.

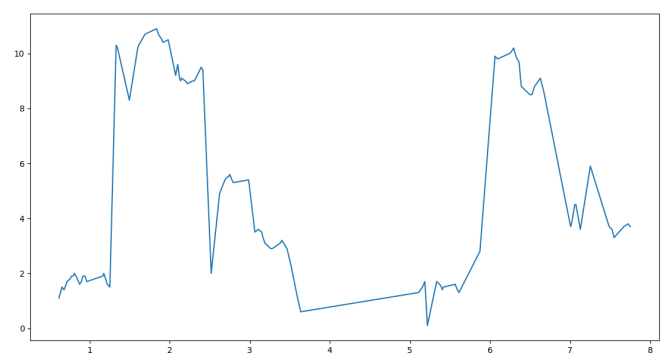

(b) Perfil de altura em classes de alturas.

Figura 2.3: Extração de $F_{0}$ com Melodia.

\section{De MIDI para $F_{0}$}

A representação de vetor de $F_{0}$ pode ser obtida facilmente apenas tomando-se a sequência

$$
P=\left(p_{0}, p_{1}, \ldots, p_{T-2}, p_{T-1}\right), T \in \mathbb{N}
$$


onde $\mathrm{T}$ representa o último valor de tempo, em ticks, e cada elemento $p_{n}$ é a altura ativa naquele momento. Um exemplo pode ser visto na figura 2.4.

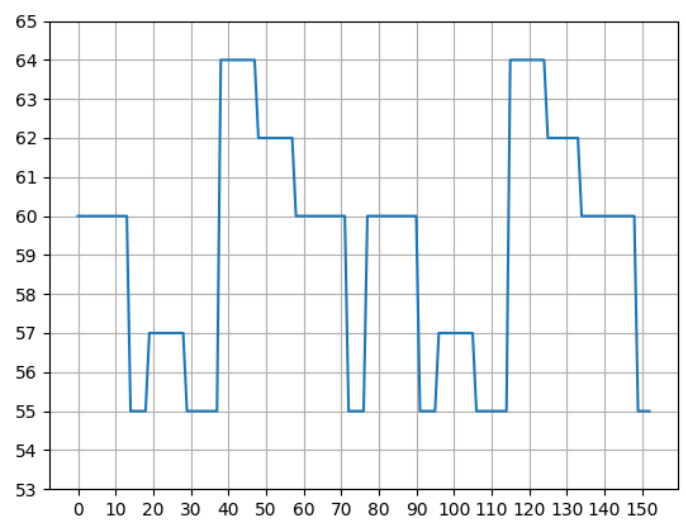

(a) Em MIDI.

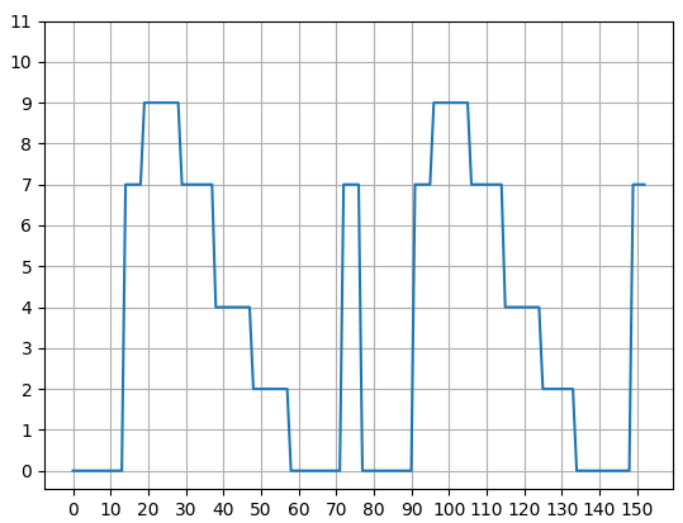

(b) Em classes de alturas.

Figura 2.4: Representações de alturas.

\section{Intervalo Musical}

A altura de um evento nem sempre é a melhor forma de comunicar informações melódicas. É muito comum a definição de um tom para a melodia, uma altura inicial que definirá os próximos eventos, com intervalos relativos a ela. Além disso, também é possível codificar uma melodia exclusivamente a partir dos intervalos formados por eventos adjacentes, como será visto a seguir.

\section{De $F_{0}$ para intervalo}

É possível tomar um vetor de alturas musicais $P$ e subtrair os valores MIDI em instantes consecutivos como

$$
I=\left(p_{1}-p_{0}, p_{2}-p_{1}, \ldots, p_{T-2}-p_{T-3}, p_{T-1}-p_{T-2}\right)
$$

o que resulta em um vetor de intervalos, que são as diferenças entre alturas de eventos MIDI. O módulo 12 do valor do intervalo pode ser utilizado para considerar classes de alturas, fazendo com que do MIDI $60(C 4)$ para o MIDI $61(C \sharp 4)$ haja o mesmo intervalo que do MIDI $60(C 4)$ para o MIDI $73(C \sharp 5)$, visto que 60 e 72 possuem ambas a mesma classe de altura $C$.

\subsubsection{Inter Onset Interval}

Onset é o momento em que se considera o início de um evento. O inter onset interval (IOI) é o intervalo em segundos entre dois onsets consecutivos. Um vetor de IOI traz informações importantes que podem ser associadas com o ritmo de uma música, principalmente quando tomada a razão entre IOIs consecutivos (IOI ratio ou IOIR).

\section{De MIDI para Onset}

De uma forma muito direta pode-se obter a lista de onsets a partir da lista MIDI. O onset é o momento de início de um evento, portanto está representada na lista MIDI, e se extraímos apenas a lista de inícios da lista MIDI teremos um vetor de onsets obtido a partir do MIDI. 


\section{De Onset para IOI}

Com um lista de onsets $Q$, pode-se tomar cada dois onsets consecutivos e calcular o IOI:

$$
I O I=\left(q_{1}-q_{0}, q_{2}-q_{1}, \ldots, q_{T-2}-q_{T-3}, q_{T-1}-q_{T-2}\right) .
$$

A partir do IOI pode-se também calcular o IOIR diretamente

$$
\operatorname{IOIR}=\left(i_{1} / i_{0}, i_{2} / i_{1}, \ldots, i_{T-2} / i_{T-3}, i_{T-1} / i_{T-2}\right) .
$$

Como os valores de duração são sempre positivos, os elementos de IOIR sempre são positivos e

$$
\begin{gathered}
i_{n} \leq i_{n-1} \Rightarrow \operatorname{IOIR} \in[0,1], \\
i_{n}>i_{n-1} \Rightarrow \operatorname{IOIR}>1 .
\end{gathered}
$$

Pode ser interessante manter os valores centrados em 0 , fazendo com que valores negativos indiquem uma redução na duração e positivos um incremento, para tal podemos tirar o logaritmo na base 2 dos elementos de IOIR na equação 2.4.

$$
\operatorname{logIOIR}=\left(\log _{2}\left(i_{1} / i_{0}\right), \log _{2}\left(i_{2} / i_{1}\right), \ldots, \log _{2}\left(i_{T-4} / i_{T-3}\right), \log _{2}\left(i_{T-3} / i_{T-2}\right)\right)
$$

A base do logaritmo poderia ser outra, mas a base 2 aproxima os valores do logIOIR dos valores obtidos na representação de intervalos, e isso é interessante para legibilidade e visualização. A figura 2.5b mostra o logIOIR da sequência vista em 2.4.

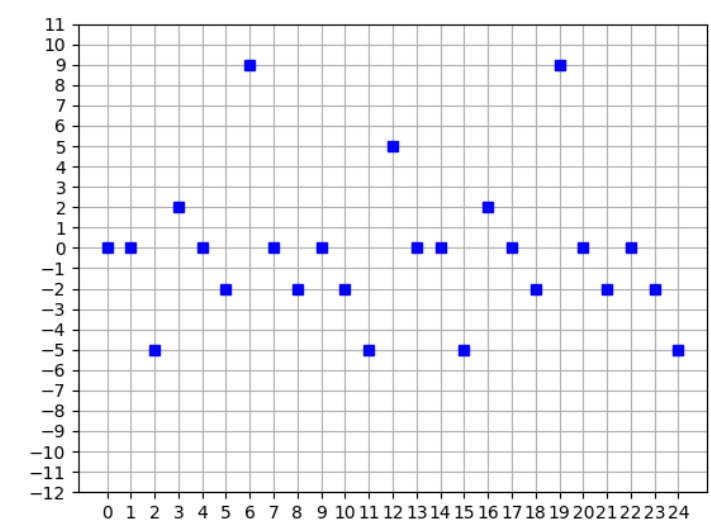

(a) Representação de intervalos.

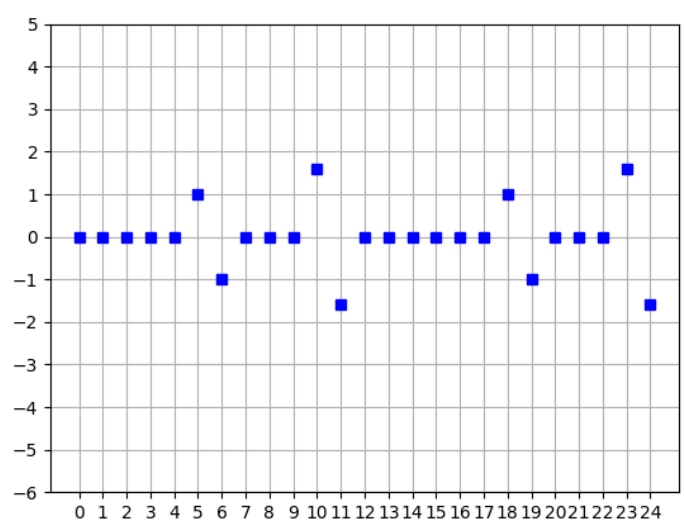

(b) Representação de durações.

Figura 2.5: Representação de intervalos e durações.

\subsubsection{Transcrição Áudio-MIDI}

Vimos a representação MIDI e também vimos como podemos utilizar áudio para extrair informações musicais. O vetor de alturas convertidas a partir das frequências fundamentais é muito útil para enxergarmos a evolução das alturas em uma gravação, mas ainda está muito longe da representação MIDI, assim como aparece em um banco de dados. Na figura 2.6, vemos um vetor de frequência fundamental extraído de uma gravação cantarolada sobreposto ao seu equivalente MIDI.

Podemos observar que há grande divergência entre as duas representações, apesar de ainda ser possível enxergar um padrão similar entre ambos quando sobrepostos. Alguns detalhes de divergência são comuns, como podemos observar. Primeiro, podemos ver que o vetor extraído do áudio possui muitas oscilações, e poucos são os momentos com maior estabilidade. Segundo, há um período de transição a cada mudança de altura, que é um período onde a pessoa cantarolando está buscando 


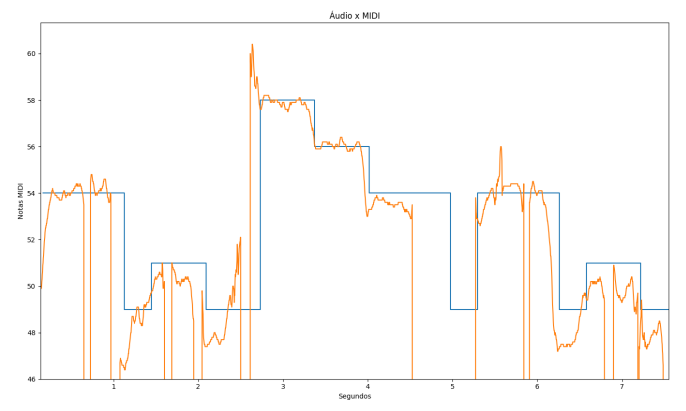

Figura 2.6: Comparação entre representação MIDI e o perfil de alturas extraído do áudio. Em azul está a altura representada no arquivo MIDI, e em laranja está o resultado obtido com gravação cantarolada.

atingir o som que possui em sua memória. Terceiro, alguns eventos mais curtos não têm períodos de estabilidade longos o suficiente para permitir uma comparação favorável. Quarto, alguns desses eventos curtos estão distantes mais de 1 semitom (150 cents, nesse exemplo) da representação MIDI.

Algumas dessas discrepâncias podem ser processadas ou filtradas para criar perfis mais próximos dos que se encontram em arquivos MIDI. Esse processo recebe o nome de transcrição. Na figura 2.7, exibimos um resultado esperado por um método de transcrição. Algoritmos de transcrição procuram estabilizar o vetor de alturas, aplicando arredondamentos, ajustes de tom e agrupamento de valores constantes.

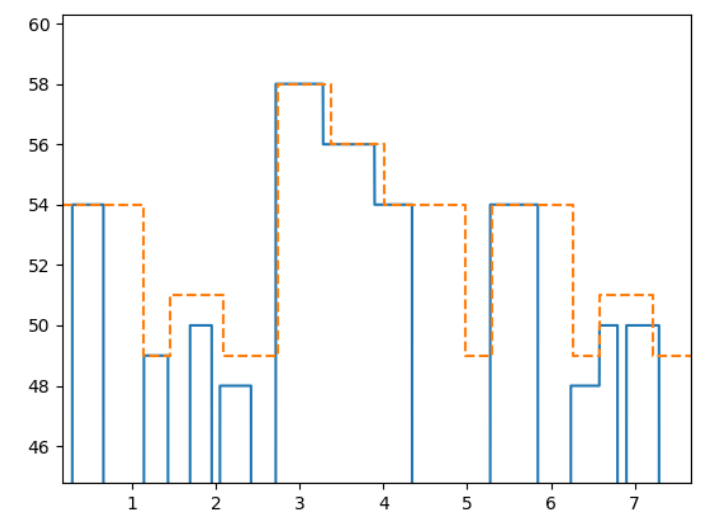

Figura 2.7: Transcrição de áudio para MIDI. Em laranja está o conteúdo do arquivo MIDI de referência. Em azul está o resultado da transcrição a partir do áudio.

\subsection{Alinhamento de subsequências}

Vetores de $F_{0}$ ou trechos de áudio são sequências, mais precisamente, são séries temporais. Sejam $X \in \mathbb{R}^{N}, Y \in \mathbb{R}^{M}, N \in \mathbb{N}, M \in \mathbb{N}$ séries temporais arbitrárias e considere uma função $c: \mathbb{R}^{N} \times \mathbb{R}^{M} \mapsto \mathbb{R}$ tal que $c(X, Y)$ representa uma medida de comparação entre as séries X e Y. Normalmente teremos restrições sobre os valores da função c, que dependem da aplicação; uma restrição comum é a desigualdade triangular, $c(X, Z) \leq c(X, Y)+c(Z, Y)$, que é válida quando $c$ representa algum tipo de distância. Tais medidas de comparação entre sequências são usadas em uma vasta quantidade de algoritmos propostos para um grande número de aplicações específicas, como por exemplo os algoritmos de Viterbi e LCSS (Maier, 1978), o DTW (White, 1978) que é discutido na seção 2.2.1 e por fim o SMBGT (Kotsifakos et al., 2011), discutido na seção 2.2.2. Os algoritmos escolhidos para discussão são comumente utilizados para alinhamento de descritores de 
áudio.

\subsubsection{Dynamic Time Warping (DTW)}

O objetivo da DTW é comparar duas séries temporais; aqui essa técnica será utilizada para alinhar consultas cantaroladas, mas poderia ser utilizada para sincronizar sequências de qualquer espécie, sejam sinais discretos, cadeias de caracteres ou informações climáticas. Para a aplicação da DTW é necessária a definição de uma função de similaridade ou dissimilaridade entre cada um dos elementos de $X=\left(x_{0}, x_{1}, \ldots, x_{N-1}\right)$ e de $Y=\left(y_{0}, y_{1}, \ldots, y_{M-1}\right)$. Especificamente, é necessária uma função $d: \mathcal{F} \times \mathcal{F} \mapsto \mathbb{R}$, considerando que $x_{n}, y_{m} \in \mathcal{F}$, sendo $\mathcal{F} \subseteq \mathbb{C}^{K}$ um espaço de características de interesse da aplicação. Exemplos de espaços $\mathcal{F}$ são aqueles definidos pela transformada de Fourier sobre sinais de áudio ou os definidos por vetores de $F_{0}$, como apresentados na seção 2.1. Definições comuns para a função d são a distância euclidiana

$$
d(u, v)=\|u-v\|
$$

que mede a dissimilaridade entre $u$ e $v$, e o valor absoluto do produto interno

$$
d(u, v)=\left|\sum_{i=0}^{K-1} u_{i} v_{i}\right|
$$

que representa uma medida de similaridade entre $u$ e $v$. A função d aplicada às séries $X$ e $Y$ pode ser representada em uma matriz D, que associará a cada par de índices $(n, m)$ o valor de $d\left(x_{n}, y_{m}\right)$, o que é ilustrado na tabela 2.2 abaixo através de um exemplo numérico.

\begin{tabular}{c|ccccc}
$y_{m} \backslash x_{n}$ & 4 & 10 & 2 & 3 & 5 \\
\hline 2 & 2 & 8 & 0 & 1 & 3 \\
10 & 6 & 0 & 8 & 7 & 5 \\
5 & 1 & 5 & 3 & 2 & 0 \\
9 & 5 & 1 & 7 & 6 & 4 \\
5 & 1 & 5 & 3 & 2 & 0 \\
5 & 1 & 5 & 3 & 2 & 0
\end{tabular}

Tabela 2.2: Ilustração de matriz D considerando $X \in \mathbb{R}^{5}, Y \in \mathbb{R}^{6}, X=(4,10,2,3,5), Y=(2,10,5,9,5,5)$ e $d(u, v)=\|u-v\|$.

Valores altos indicam que as sequências são muito dissimilares naquele par de índices, e a tarefa do DTW é percorrer a matriz D entre os índices $(0,0)$ e $(\mathrm{N}-1, \mathrm{M}-1)$ fazendo um caminho que acumule a menor soma possível das medidas de dissimilaridade. Em um exemplo mais prático, pode-se ver na figura 2.8 como se comporta uma matriz S de similaridade no caso da comparação de uma sequência consigo própria, gerada a partir de uma música, considerando como características os cromagramas, que são vetores em $R^{12}$, e tomando a função de similaridade dada pelo valor absoluto do produto interno. O produto interno gera valores altos em pares com alta similaridade, portanto a interpretação da escala é oposta em relação à tabela 2.2. Podemos observar que a faixa de valores onde elementos com mesmo índice são comparados (na diagonal, que neste caso corresponde exatamente ao mesmo elemento nas duas sequências) possuem valores altos. É possível observar outras faixas de valores altos paralelas à diagonal, sugerindo que a música repita certos padrões ao longo do tempo.

A partir das sequências $\mathrm{X}$ e $\mathrm{Y}$ e da matriz $\mathrm{D}$, define-se um caminho em $\mathrm{D}$ como uma sequência $P=\left(p_{0}, p_{1}, \ldots, p_{L-2}, p_{L-1}\right)$, onde cada elemento é uma dupla $p_{l}=\left(n_{l}, m_{l}\right)$ que representa a posição $n_{l}$ em X e $m_{l}$ em Y. Algumas regras alteram o comportamento do caminho, como as fronteiras iniciais e finais (que são definidas como $(0,0)$ e (N-1,M-1) quando a intenção é comparar apenas as sequências inteiras) e a restrição dos tipos de passo, por exemplo $p_{l}-p_{l-1} \in\{(1,0),(0,1),(1,1)\}$ 


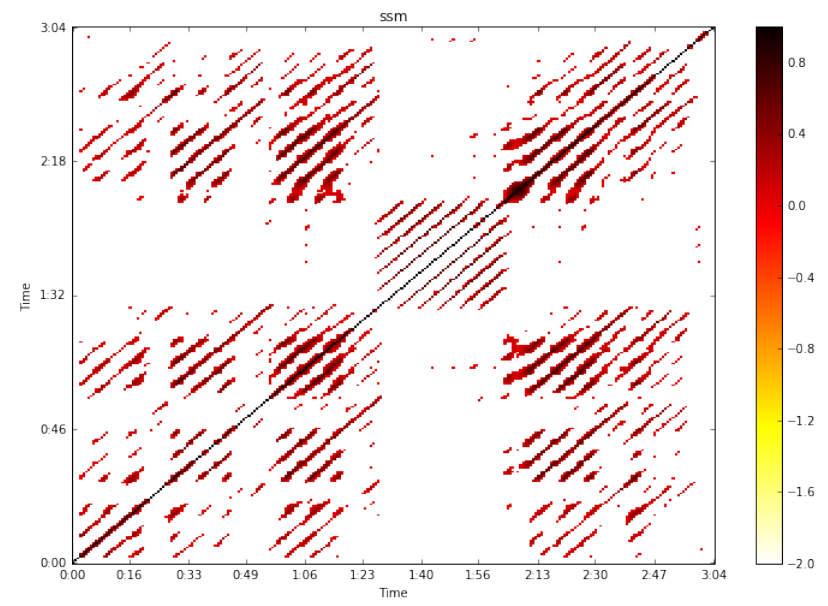

Figura 2.8: Matriz D quando produzida a partir de uma música comparada a si mesma.

para $l \in[1: L-1]$ para indicar que o caminho deve usar exclusivamente passos na vertical, horizontal e diagonal, respectivamente.

A fim de se computar o melhor alinhamento entre $X$ e $Y$ define-se a função $c_{P}(X, Y)$ para cálculo do custo acumulado associado a um caminho $\mathrm{P}$ de tamanho L, dada por

$$
c_{P}(X, Y)=\sum_{l=0}^{L-1} D\left(n_{l}, m_{l}\right),
$$

ou seja, a soma das medidas de dissimilaridade das posições na matriz que o caminho percorre. Exemplos de caminhos e seus custos acumulados podem ser vistos na figura 2.9. Uma forma de obter o caminho ótimo seria realizar o cálculo de $\mathrm{c}(\mathrm{X}, \mathrm{Y})$ para todas os caminhos possíveis $\mathrm{P}$, o que corresponde a um algoritmo de força bruta que tem custo exponencial no tamanho das sequências; mas esse problema de otimização pode ser resolvido por um algoritmo de programação dinâmica de complexidade $\mathcal{O}(M N)$. A idéia da programação dinâmica é uma estratégia de divisão e conquista que explora a relação entre o valor ótimo do problema original e de subproblemas, permitindo a solução do problema utilizando recursão.

\begin{tabular}{|c|c|c|c|c|c|c|c|c|c|c|}
\hline$y_{m} \backslash x_{n}$ & 4 & 10 & 2 & 3 & 5 & $y_{m} \backslash x_{n}$ & 4 & 10 & 2 & 3 \\
\hline 2 & 2 & 8 & 0 & 1 & 3 & 2 & 2 & 8 & 0 & 1 \\
\hline 10 & 6 & 0 & 8 & 7 & 5 & 10 & 6 & $\mathrm{O}_{2}$ & 8 & 7 \\
\hline 5 & 1 & $5^{13}$ & 3 & 2 & 0 & 5 & 1 & 5 & & 27 \\
\hline 9 & 5 & 1 & $7^{20}$ & & 4 & 9 & 5 & 1 & 7 & 6 \\
\hline 5 & 1 & 5 & 3 & $2^{22} \rightarrow$ & $-0^{22}$ & 5 & 1 & 5 & 3 & 2 \\
\hline 5 & 1 & 5 & 3 & 2 & $0^{22}$ & 5 & 1 & 5 & 3 & 2 \\
\hline
\end{tabular}

(a) Caminho que obteve custo acumulado 22.

(b) Caminho que obteve custo acumulado 11.

Figura 2.9: Exemplo de caminhos com seus custos acumulados. Vemos que a figura da direita teve um custo menor.

No caso da DTW, o algoritmo se baseia na definição de uma matriz $C(n, m)$ de tamanho $N \times M$ que representa o custo ótimo do subproblema de alinhar as sequências parciais $X^{n}=\left(x_{0}, x_{1}, \ldots, x_{n}\right)$ 
e $Y^{m}=\left(y_{0}, y_{0}, \ldots, y_{m}\right)$, sendo definida recursivamente por:

$$
\begin{gathered}
C(n, 0)=\sum_{i=0}^{n} D(i, 0) \quad \text { para } n \in[0: N-1], \\
C(0, m)=\sum_{i=0}^{m} D(0, i) \quad \text { para } m \in[0: M-1], \\
C(n, m)=D(n, m)+\min \{C(n-1, m-1), C(n-1, m), C(n, m-1)\} \text { para } n, m>0 .
\end{gathered}
$$

onde a equação 2.8 considera que os passos estão definidos para o conjunto $\{(1,0),(0,1),(1,1)\}$, e deve ser adaptada para outros contextos com passos diferentes. A demonstração da otimalidade dessa estratégia pode ser encontrada, por exemplo, em (Müller, 2015).

As equações (2.6) e (2.7) inicializam a recursão, e a computação segue com o cálculo de $(2.8)$ que pode ser feito numa varredura por linhas ou por colunas da matriz C. No último passo, quando $n=N-1$ e $m=M-1$, o alinhamento ótimo terá valor associado $\operatorname{DTW}(X, Y)=C(n, m)$. Os pares associados ao caminho $P$ ótimo podem ser obtidos por backtracking a partir da posição $(n, m)$ da matriz, considerando em cada aplicação da equação (2.8) qual dos termos realizou o mínimo correspondente.

Caso o interesse seja apenas obter o resultado de $\operatorname{DTW}(X, Y)$, seria possível armazenar apenas a coluna/linha anterior na varredura correspondente. Isso reduz o requisito de armazenamento em memória de $\mathcal{O}(N M)$ para $\mathcal{O}(N)$ (ou $\mathcal{O}(M)$ ). Ainda assim, o processamento de (2.8) é realizado $(N-1)(M-1)$ vezes, e portanto a complexidade de computação permanecerá $\mathcal{O}(N M)$.

Utilizando a matriz D do exemplo da tabela 2.2 e as equações 2.6, 2.7 e 2.8, calculamos a tabela 2.3, que mostra na parte inferior a matriz C com o resultado do DTW na posição $(4,5)$ com valor ótimo de alinhamento $\operatorname{DTW}(X, Y)=11$.

\subsubsection{Alinhamento inexato}

Nesta seção discutiremos o algoritmo SMBGT (Kotsifakos et al., 2011) para alinhamento inexato de subsequências que foi proposto especificamente para aplicações de recuperação musical, mas por se tratar de um algoritmo genérico de comparação de subsequências, também é aplicável a outras áreas. A ideia do alinhamento inexato é comparar subsequências de $X=\left(x_{0}, x_{1}, \ldots, x_{N-2}, x_{N-1}\right)$ e $Y=\left(y_{0}, y_{1}, \ldots, y_{N-2}, y_{N-1}\right)$; especificamente, uma subsequência de $X$ tem a forma $X^{\prime}=X\left[t_{0}: t_{1}\right]=$ $\left(x_{t_{0}}, \ldots, x_{t_{1}}\right)$, onde $t_{0}<t_{1}$. A inexatidão no alinhamento prevê que divergências entre as duas sequências não gerem falsos negativos, visto que no domínio de aplicação dificilmente a consulta gravada será precisamente igual à representação contida no banco de dados. Para tal, a estratégia utilizada é permitir subsequências que têm lacunas na faixa de índices (e.g. a subsequência $\left(x_{2}, x_{3}, x_{6}, x_{7}\right)$ tem uma lacuna pois os índice 4 e 5 estão ausentes). Uma estratégia secundária é permitir tolerância para medidas de similaridade entre elementos, de forma que $x_{n} \approx_{f\left(x_{n}\right)} y_{m}$ denota que $x_{n}$ e $y_{m}$ têm aproximadamente o mesmo valor, com uma tolerância $f$ definida em função de $x_{n}$. Para oferecer controle sobre a tolerância de erros, fatores $\alpha$ e $\beta$ são definidos para limitar o tamanho das lacunas em X e Y, respectivamente.

Será definida uma matriz $C(n, m)$ de tamanho $(N+1) \times(M+1)$ por recursão:

$$
\begin{gathered}
C(n, 0)=0, C(0, m)=0, \\
C(n, m)= \begin{cases}C(n-1, m-1)+1, & \text { se } x_{n-1} \approx_{f\left(x_{n-1}\right)} y_{m-1} \\
\max \{C(n-1, m), C(n, m-1)\}, & \text { caso contrário }\end{cases}
\end{gathered}
$$

Para a computação da matriz $C(m, n)$, a equação 2.9 inicializa a recursão, que se segue através do cálculo da equação 2.10 numa varredura por linhas ou por colunas da matriz. A matriz $C(m, n)$ 


\begin{tabular}{c|ccccc}
\hline $\mathrm{D}$ & $x_{0}=4$ & $x_{1}=10$ & $x_{2}=2$ & $x_{3}=3$ & $x_{4}=5$ \\
\hline$y_{0}=2$ & 2 & 8 & 0 & 1 & 3 \\
$y_{1}=10$ & 6 & 0 & 8 & 7 & 5 \\
$y_{2}=5$ & 1 & 5 & 3 & 2 & 0 \\
$y_{3}=9$ & 5 & 1 & 7 & 6 & 4 \\
$y_{4}=5$ & 1 & 5 & 3 & 2 & 0 \\
$y_{5}=5$ & 1 & 5 & 3 & 2 & 0 \\
\hline
\end{tabular}

(a) Matriz D.

\begin{tabular}{c|ccccc}
\hline $\mathrm{C}$ & $x_{0}=4$ & $x_{1}=10$ & $x_{2}=2$ & $x_{3}=3$ & $x_{4}=5$ \\
\hline$y_{0}=2$ & 2 & $(2+8)=10$ & $(10+0)=10$ & $(10+1)=11$ & $(11+3)=14$ \\
$y_{1}=10$ & $(2+6)=8$ & $(\min \{2,10,8\}+0)=2$ & $(\min \{10,10,2\}+8)=10$ & $\ldots$ & $\ldots$ \\
$y_{2}=5$ & $(8+1)=9$ & $(\min \{8,2,9\}+5)=7$ & $(\min \{2,10,7\}+3)=5$ & $\ldots$ & $\ldots$ \\
$y_{3}=9$ & $(9+5)=14$ & $\vdots$ & $\vdots$ & $\ddots$ & \\
$y_{4}=5$ & $(14+1)=15$ & $\vdots$ & $\vdots$ & & \\
$y_{5}=5$ & $(15+1)=16$ & $\vdots$ & $\vdots$ & & $\ddots$ \\
\hline
\end{tabular}

(b) Cálculo passo-a-passo.

\begin{tabular}{c|ccccc}
\hline $\mathrm{C}$ & $x_{0}=4$ & $x_{1}=10$ & $x_{2}=2$ & $x_{3}=3$ & $x_{4}=5$ \\
\hline$y_{0}=2$ & 2 & 10 & 10 & 11 & 14 \\
$y_{1}=10$ & 8 & 2 & 10 & 17 & 16 \\
$y_{2}=5$ & 9 & 7 & 5 & 7 & 7 \\
$y_{3}=9$ & 14 & 8 & 12 & 13 & 11 \\
$y_{4}=5$ & 15 & 13 & 11 & 13 & 11 \\
$y_{5}=5$ & 16 & 18 & 14 & 13 & 11 \\
\hline
\end{tabular}

(c) Matriz resultante $C$.

Tabela 2.3: Ilustração da computação de $C$.

associada ao exemplo anterior está ilustrada na tabela 2.4, considerando $f\left(x_{n}\right)=0$ para $n \in$ $[0, N-1]$.

\begin{tabular}{c|cccccc}
\hline $\mathrm{C}$ & $\mathrm{n}=0$ & $x_{0}=4$ & $x_{1}=10$ & $x_{2}=2$ & $x_{3}=3$ & $x_{4}=5$ \\
\hline$m=0$ & 0 & 0 & 0 & 0 & 0 & 0 \\
$y_{0}=2$ & 0 & 0 & 0 & 1 & 1 & 1 \\
$y_{1}=10$ & 0 & 0 & 1 & 1 & 1 & 1 \\
$y_{2}=5$ & 0 & 0 & 0 & 1 & 1 & 2 \\
$y_{3}=9$ & 0 & 0 & 0 & 1 & 1 & 2 \\
$y_{4}=5$ & 0 & 0 & 0 & 1 & 1 & 2 \\
$y_{5}=5$ & 0 & 0 & 0 & 1 & 1 & 2 \\
\hline
\end{tabular}

Tabela 2.4: Ilustração da computação de $C$, com $f\left(x_{n}\right)=0$, considerando $X=(4,10,2,3,5)$ e $Y=$ $(2,10,5,9,5,5)$.

Para implementar a restrição associada a $\alpha$ e $\beta$, é necessário armazenar separadamente os valores de índice onde $x_{n-1} \approx_{f\left(x_{n-1}\right)} y_{m-1}$ em vetores $L_{x}$ (de tamanho N) e $L_{y}$ (de tamanho M), e adicionar uma condição em 2.10, produzindo a seguinte atualização: 


$$
C(n, m)= \begin{cases}C(n-1, m-1)+1, & \text { se } x_{n-1} \approx_{f\left(x_{n-1}\right)} y_{m-1} \\ 0, & \text { se } n-L_{x}(n)>\alpha e m-L_{y}(m)>\beta \\ C(n, m-1), & \text { se } n-L_{x}(n)>\alpha \\ C(n-1, m), & \text { se } m-L_{y}(m)>\beta \\ \max \{C(n-1, m), C(n, m-1)\}, & \text { caso contrário }\end{cases}
$$

Por fim, temos que

$$
S M B G T(X, Y)=\max \{C(m, n) \text { para } n \in[0: N+1], m \in[0: M+1]\}
$$

A matriz $C(m, n)$ do exemplo anterior com $f\left(x_{n}\right)=0.5 x_{n}, \alpha=2$ e $\beta=1$ está ilustrada na tabela 2.5. Os valores que aparecem na tabela indicam o tamanho da subsequência que está sendo comparada até o momento. Um valor alto mostra que o tamanho da subsequência está se aproximando de N (valor máximo obtenível), e se uma subsequência grande consegue ser alinhada a Y, então temos um bom alinhamento, pois ambas têm muitos elementos semelhantes (no sentido que $\left.x_{n-1} \approx_{f\left(x_{n-1}\right)} y_{m-1}\right)$.

\begin{tabular}{c|cccccc}
\hline $\mathrm{C}$ & $\mathrm{n}=0$ & $x_{0}=4$ & $x_{1}=10$ & $x_{2}=2$ & $x_{3}=3$ & $x_{4}=5$ \\
\hline$m=0$ & 0 & 0 & 0 & 0 & 0 & 0 \\
$y_{0}=2$ & 0 & 0 & 0 & 1 & 1 & 1 \\
$y_{1}=10$ & 0 & 0 & 1 & 1 & 1 & 1 \\
$y_{2}=5$ & 0 & 1 & 1 & 1 & 1 & 2 \\
$y_{3}=9$ & 0 & 0 & 2 & 2 & 2 & 2 \\
$y_{4}=5$ & 0 & 1 & 1 & 2 & 2 & 3 \\
$y_{5}=5$ & 0 & 1 & 2 & 2 & 2 & 3 \\
\hline
\end{tabular}

Tabela 2.5: Ilustração da computação de C. $f\left(x_{n}\right)=0.5 x_{n}, \alpha=2, \beta=1$.

Mais detalhes sobre o SMBGT podem ser encontrados em (Kotsifakos et al., 2011).

\subsection{Métricas de Avaliação}

Foram descritas na seção anterior maneiras de calcular características que permitem uma comparação, através de medidas de similaridade, entre sequências. No entanto essas medidas não criam significado sem um contexto de aplicação e, mesmo definindo-se esse contexto, não discutimos ainda formas de avaliar se tais algoritmos estão realmente satisfazendo as necessidades descritas pelo contexto de aplicação. Para a busca cantarolada normalmente será avaliado se o sistema está de fato identificando a música que foi cantada. Especificamente, a partir de uma gravação cantada que tem intenção de representar a música X, uma forma simples de avaliar a resposta do sistema seria: se respondeu X, funciona, caso contrário não funciona. Diferentemente de muitos problemas em recuperação de informação musical, esse tipo de avaliação bastante simples e aparentemente não problemática não representa uma abordagem perfeita, já que é difícil saber de antemão, por exemplo, se a música cantada é de fato reconhecível mesmo por avaliadores humanos, ainda que se conheça a intenção do interlocutor de cantar a música X. Para efeito de simplificação, nesse estudo será considerado que todas as gravações fornecidas são gravações reconhecíveis, e discutiremos técnicas para automação do cálculo da proximidade dos resultados estimados com os resultados de referência. Serão discutidas as métricas de precision e recall (seção 2.3.1) e mean reciprocal rank (seção 2.3.2), medidas comuns para avaliações em recuperação de informação musical. 


\subsubsection{Precision e recall}

As medidas de precision e recall são originalmente definidas num contexto de rotulação, onde há duas classes de elementos, positivos e negativos, e um mecanismo de rotulação que pretende produzir os rótulos corretos. De forma direta, precision pode ser caracterizada como a fração de elementos rotulados corretamente como positivos dentre todos os elementos rotulados como positivos, e recall como a fração dos elementos rotulados corretamente como positivos dentre todos os elementos verdadeiramente positivos. No caso de um algoritmo que produz respostas a uma consulta, consideramos dentre um conjunto de respostas possíveis $\mathrm{P}$ um conjunto $\mathrm{R}$ que indica as respostas de referência e um conjunto $\mathrm{E}$ que contém as respostas estimadas. O conjunto de respostas em $\mathrm{P}$ que não estão em $\mathrm{R}$ será denotado por R', e analogamente as respostas em $\mathrm{P}$ que não estão em E serão denotadas por E'. O conjunto $E \cap R$ será denotado como VP, os verdadeiros positivos, o número de elementos em VP será denotado \#VP. Similarmente $E \cap R^{\prime}=F P$ representa os falsos positivos, $E^{\prime} \cap R=F N$ os falsos negativos e $E^{\prime} \cap R^{\prime}=V N$ os verdadeiros negativos, conforme a tabela 2.6. Por fim, definem-se as medidas de precision e recall como

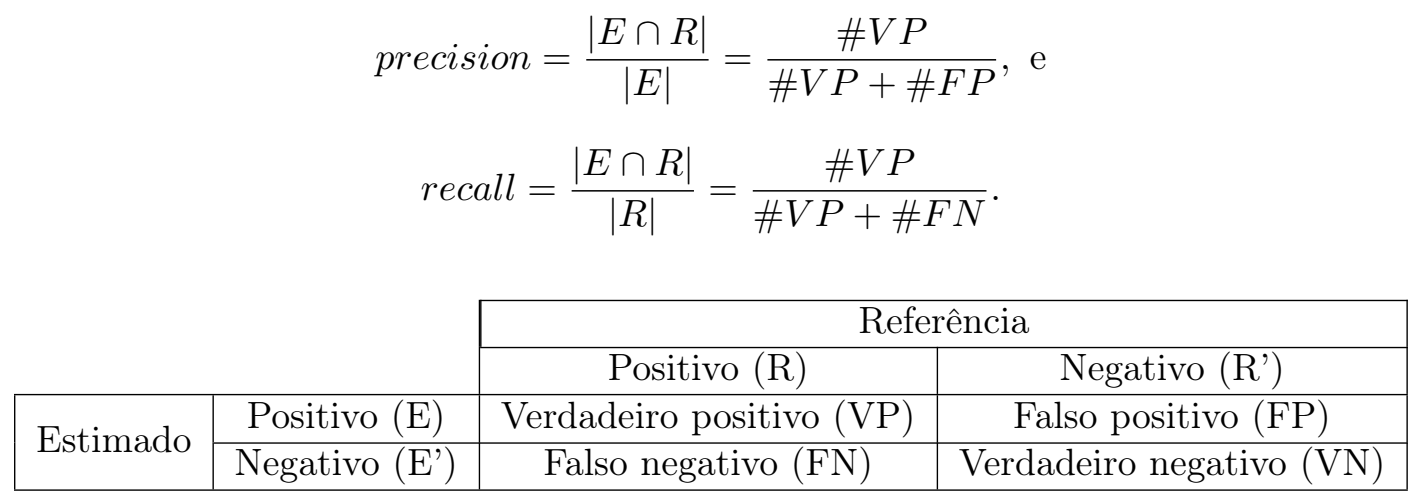

Tabela 2.6: Conjuntos usados nas definições de precision e recall

Observe que essas medidas estão sempre dentro do intervalo [0,1], já que nas duas métricas o conjunto no numerador é subconjunto daquele do denominador. Considera-se nos dois casos que 1 é o melhor valor possível (caso $\mathrm{E}=\mathrm{R}$ ), e valores próximos de 1 indicam que $\mathrm{E}$ e $\mathrm{R}$ possuem muitos elementos em comum.

Como exemplo diretamente relacionado à consulta cantarolada, tome uma lista de músicas $M=\left(M_{1}, M_{2}, M_{3}, M_{4}, M_{5}\right)$ e uma lista de consultas $C=\left(C_{1}, C_{2}, C_{3}, C_{4}, C_{5}\right)$. O conjunto de respostas possíveis $\mathrm{P}$ será a coleção de todos os pares de itens em $\mathrm{M}$ e $\mathrm{C}$ :

$$
P=\left\{\left(C_{i}, M_{j}\right) \mid i=1, \ldots, 5, j=1, \ldots, 5\right\} .
$$

Considere que o conjunto de referência é

$$
R=\left\{\left(C_{1}, M_{1}\right),\left(C_{2}, M_{2}\right),\left(C_{3}, M_{3}\right),\left(C_{4}, M_{4}\right),\left(C_{5}, M_{5}\right)\right\},
$$

o que indica que cada consulta $C_{i}$ estava associada à música $M_{i}$ de mesmo índice.

Considere agora que o sistema de busca devolva o seguinte conjunto estimado:

$E=\left\{\left(C_{1}, M_{1}\right),\left(C_{1}, M_{2}\right),\left(C_{2}, M_{4}\right),\left(C_{2}, M_{5}\right),\left(C_{3}, M_{1}\right),\left(C_{3}, M_{3}\right),\left(C_{4}, M_{3}\right),\left(C_{4}, M_{4}\right),\left(C_{5}, M_{4}\right),\left(C_{5}, M_{5}\right)\right\}$

onde a cada consulta o sistema produz duas alternativas de músicas possíveis (resposta do tipo "top 2"). O conjunto de verdadeiros positivos nesse caso será

$$
V P=E \cap R=\left\{\left(C_{1}, M_{1}\right),\left(C_{3}, M_{3}\right),\left(C_{4}, M_{4}\right),\left(C_{5}, M_{5}\right)\right\}
$$


e então temos

$$
\begin{gathered}
\text { precision }=\frac{|E \cap R|}{|E|}=\frac{4}{10}=0.4 \mathrm{e} \\
\text { recall }=\frac{|E \cap R|}{|R|}=\frac{4}{5}=0.8
\end{gathered}
$$

Podemos notar um comportamento padrão em sistemas de busca: quanto maior o número de elementos retornados na busca, menor será a medida de precision, pois a busca produzirá resultados indesejados. No exemplo anterior, em que o sistema sempre devolve duas alternativas para cada consulta, a medida de precision já está de antemão limitada ao valor máximo 0.5 (já que $E$ terá o dobro do tamanho de $R$ ). Analogamente, a medida de recall será beneficiada por um número grande de itens retornados, sendo que, no exemplo mostrado, a utilização de respostas top 5 resultaria em recall $=1$ para qualquer o processamento que tivesse sido feito, pois nesse caso $R \subseteq E$ e portanto $E \cap R=R$.

\subsubsection{Mean Reciprocal Rank (MRR)}

O mean reciprocal rank é uma métrica utilizada quando há uma lista de resultados ordenados e se quer avaliar a posição em que respostas corretas aparecem. A ideia dessa medida é oferecer uma informação complementar ao precision, pois em consultas com $N$ respostas o precision estará limitado a priori em $\frac{1}{N}$ como visto no último exemplo (ou seja, essa métrica se torna menos relevante quanto maior for o número de respostas que o sistema fornece). Reciprocal rank significa literalmente o inverso da posição em que aparece o resultado,

$$
R R_{i}=\frac{1}{\operatorname{rank}_{i}}
$$

de onde se obtém a expressão do mean reciprocal rank como a média desses valores inversos de posição para um conjunto de consultas C:

$$
M R R=\frac{1}{|C|} \sum_{i=0}^{|C|-1} \frac{1}{r a n k_{i}} .
$$

Note que isso corresponde exatamente ao inverso da média harmônica das posições das respostas corretas; em particular $M R R \in(0,1]$ e quanto mais próximas da primeira posição estiverem as respostas corretas, mais próximo de 1 será o valor do MRR. Como exemplo simples, pensando em um conjunto com 5 consultas $\mathrm{C}$ que devolvem múltiplas respostas, e onde os resultados corretos aparecem respectivamente nas posições rank $=(2,4,4,10,1)$, essas consultas possuem

$$
M R R=\frac{\frac{1}{2}+\frac{1}{4}+\frac{1}{4}+\frac{1}{10}+\frac{1}{1}}{5}=0.42
$$

de onde a média harmônica das posições corretas pode ser obtida como $M R R^{-1}=2.38$. Sabe-se entretanto que a média harmônica tende a se aproximar dos valores mais baixos da coleção, sendo menor do que as médias geométrica e aritmética, e por isso essa posição média deve ser interpretada com cautela (no exemplo anterior apenas 2 das 5 consultas estão entre as "2.38 primeiras posições"). 


\section{Capítulo 3}

\section{Metodologia}

De forma parecida ao proposto em (Dannenberg et al., 2007), seguiremos o processo de enviar um conjunto de dados comum para diversos mecanismo de busca e, em seguida, medir a eficiência para conseguir compará-los. O tipo de dado de entrada e o processo de realização das buscas serão ligeiramente diferentes ao longo dos diferentes casos estudados, pois temos interesse em avaliar diferentes cenários. A figura 3.1a mostra como será realizada a medição para cada consulta. O banco de dados pode ser usado ou não no alinhamento, no caso da ferramenta de rankeamento já possuir um banco de dados próprio. A figura 3.1b mostra o processo de rankeamento, onde uma consulta será alinhada com cada melodia do banco para obtenção da lista ordenada de scores. Nenhum algoritmo de hashing ou listas invertidas será utilizado, pois não é o foco deste trabalho a otimização do tempo de processamento, além de este tipo de algoritmo não ser facilmente aplicável com alinhamento de subsequências. Para efeito de comparação de resultados, o banco de dados de partida de todos os cenários será o mesmo, então os cenários e o banco devem ser compatíveis entre si. Nas próximas seções descreveremos a metodologia para seleção de banco de dados, métricas e cenários.

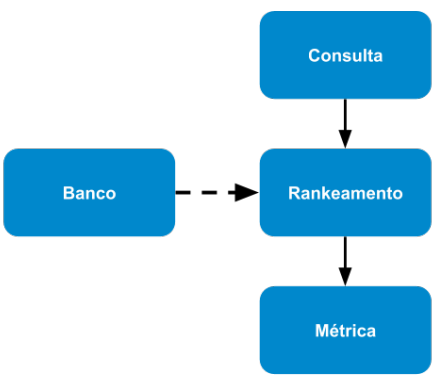

(a) Consultas serão rankeadas e medidas.

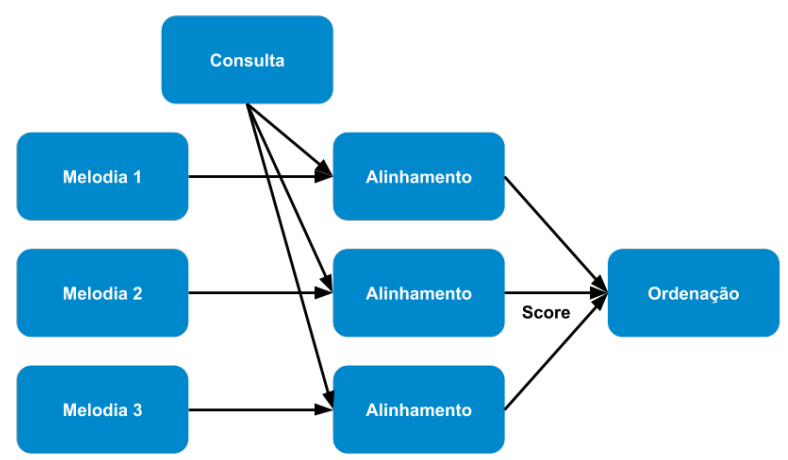

(b) O rankeamento envolve o alinhamento da consulta com cada uma das melodias conhecidas.

Figura 3.1: Fluxos do processamento para uma consulta cantarolada.

\subsection{Estrutura}

\subsubsection{Banco de dados}

A escolha do banco de dados tem grande impacto no decorrer dos experimentos realizados. Ele afeta o tipo de resultado esperado, pois, por exemplo, um maior número de melodias distintas presentes nele afeta a dificuldade de se encontrar uma amostra específica, já que se torna menor a probabilidade de escolhê-la ao acaso. Ele também afeta a confiabilidade do resultado, visto que quanto mais consultas forem utilizadas, com maior número de pessoas distintas cantarolando, maior 
o número de casos cobertos no experimento, fazendo com que seja mais provável que os resultados se repitam em casos semelhantes. Igualmente, o banco será responsável pela reprodutibilidade dos experimentos, pois se o banco de dados tiver seu acesso restrito de alguma forma, não será possível a qualquer pessoa interessada reproduzi-los. Nesta seção o detalhamento do banco será realizado como no esquema observado na figura 3.2.

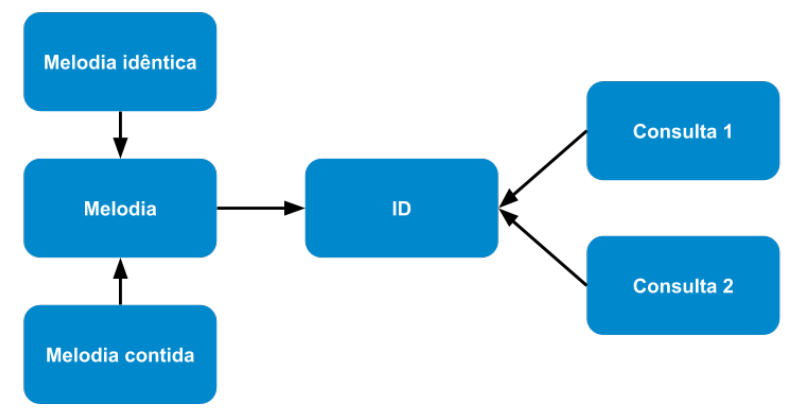

Figura 3.2: Relação entre identificador e melodias/consultas.

Cada uma das melodias incluídas no banco deve estar associada a um identificador único. As melodias devem ser monofônicas, ou as músicas devem estar separadas em diversas linhas melódicas. As melodias podem ter qualquer duração temporal e podem ser semelhantes entre si, porém não é desejável que o banco possua duas melodias exatamente iguais rotuladas como sendo distintas, sendo que isso inclui o caso onde uma melodia está inteiramente contida em outra. Casos onde 2 melodias idênticas recebem identificadores diferentes causam dificuldades no momento da avaliação dos resultados, onde apenas uma resposta é considerada correta.

O banco também deve possuir consultas cantaroladas, cada uma associada a uma das melodias da qual se tem informações. Cada uma das consultas do banco deve estar associada a uma melodia, através do identificador único. Assim, será possível automatizar a identificação de qual será a resposta esperada. As consultas devem possuir gravações de áudio, com indivíduos cantarolando as melodias. Cada melodia presente no banco deve ter uma representação simbólica associada, também através do identificador único. A representação simbólica deve conter todo o conteúdo da melodia. As gravações cantaroladas não precisam ter o conteúdo inteiro, mas um trecho inicial da melodia.

\subsubsection{Métricas}

A avaliação dos resultados tem que ser feita de forma clara e de tal maneira que os resultados de diferentes experimentos sejam comparáveis quantitativamente. Para isso, calcularemos a porcentagem de consultas que não retornam resultados esperados, a fim de explicitar a porcentagem do banco de dados que não é atendida pela abordagem testada. Também calcularemos o reciprocal rank, pois ele qualifica os resultados obtidos, produzindo valores máximos para as consultas que produzem resultados corretos na primeira posição de um rank, sem deixar bonificar consultas que produziram resultados em outras posições do início da lista. Ambas as métricas serão computadas por melodia e também será tomada a média geral. Iremos considerar resultados acima de $90 \%$ como confiáveis, acreditando que essa é uma porcentagem satisfatória para uma tarefa que não requer resultados tão rígidos, já que seriam esperados erros mesmo se a tarefa fosse realizada por especialistas humanos, e erros também não são graves no sentido do impacto causado.

\subsection{Cenários}

Analisaremos alguns cenários experimentais com a intenção de explorar alguns modos diferentes para realizar buscas usando consulta cantarolada. Dessa forma tentaremos mapear o estado-da-arte atual dessa tarefa, assim como identificar pontos relevantes para investigações e melhorias, de forma que seja possível aprimorar as estratégias de busca. 


\subsubsection{Avaliação de uma ferramenta existente}

Para este cenário, utilizaremos uma ferramenta de consulta cantarolada que tenha uma interface aberta para envio de consultas e que permita o envio em lote, devolvendo resultados encontrados para cada uma das consultas, como exibido na figura 3.3. É importante que a ferramenta seja aberta e gratuita, pensando tanto em sua ampla utilização como na reprodutibilidade deste trabalho. Utilizaremos o próprio áudio do banco como consulta, que será enviado ao sistema. Utilizaremos as métricas de MRR e recall sobre as respostas para medir a qualidade do sistema.

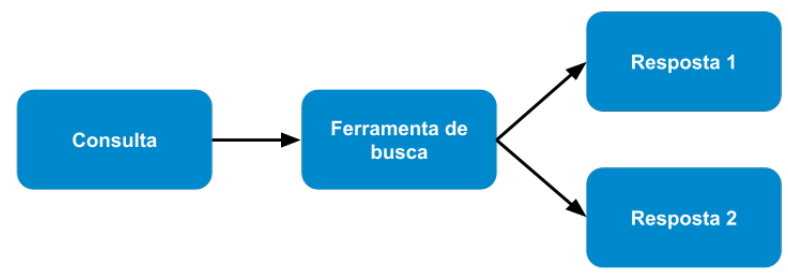

Figura 3.3: A ferramenta de busca cantarolada recebe uma consulta e retorna uma lista de respostas.

A interface deve possibilitar a automatização do envio das consultas. Espera-se que os resultados também sejam devolvidos de forma que seja fácil sua leitura automatizada para anotação do resultado da consulta. É desejável que a ferramenta de busca possua código aberto para permitir a checagem dos resultados obtidos.

As melodias identificáveis pela ferramenta devem ser conhecidas, estando listadas de forma clara para permitir a ciência antecipada de quais consultas não serão identificadas porque a ferramenta não conhece as respectivas músicas (um caso que não interessa testar), e quais não serão identificadas por falha de associação da consulta com a resposta no banco (caso de interesse). Para ser possível a automatização da leitura dos resultados, faz-se necessário mapear as melodias presentes na ferramenta e os identificadores existentes no banco.

O método de alinhamento e criação de ranking da ferramenta é importante e deve ser descrito em detalhe. É desejável que o alinhamento possua um modelo como o utilizado nos próximos cenários, pois assim será possível comparar ferramentas de acordo com a metodologia de busca.

\subsubsection{Sequências de alturas}

Neste cenário mediremos a eficiência de um algoritmo baseado no alinhamento de sequências melódicas simplificadas, que crie um ranking utilizando a transcrição da consulta em áudio para uma sequência contendo apenas alturas, como exibido na figura 3.4. Uma metodologia semelhante é usada em Tararira (López et al., 2004), que usa uma codificação simbólica para alinhar itens do banco de dados, mas além da informação de altura o algoritmo usa também a informação temporal. Este tipo de abordagem também é visto em SMBGT (Kotsifakos et al., 2011), que utiliza uma algoritmo de alinhamento de representações simbólicas com parâmetros de controle para tolerância de variância entre as séries e tamanho de subsequências. A mesma abordagem também é utilizada para comparação em (Dannenberg et al., 2007).

O algoritmo de alinhamento utilizará a sequência obtida a partir da representação simbólica da melodia da entrada. A sequência representa a evolução das alturas ao longo da melodia, sem a restrição de especificar o momento de início e a duração dos eventos. A intenção é obter uma representação simples e compacta, mas que carregue características distintivas da melodia. Uma tal representação é utilizada, por exemplo, em coletâneas de temas musicais em livros impressos (Barlow e Morgenstern, 1966, 1975). Tal representação será utilizada como base de conhecimento para o alinhamento.

O alinhamento deve retornar uma nota (score) para cada par consulta/melodia e ordenar as melodias com base nela (ranking). Cada consulta será transcrita de áudio para sequência de alturas e então alinhada para gerar o score e obter o ranking. O alinhamento deveria relevar momentos de incompatibilidade entre as sequências de alturas, assim como permitir uma tolerância entre seus elementos. Espera-se que a resposta correta apareça entre os primeiros resultados. 


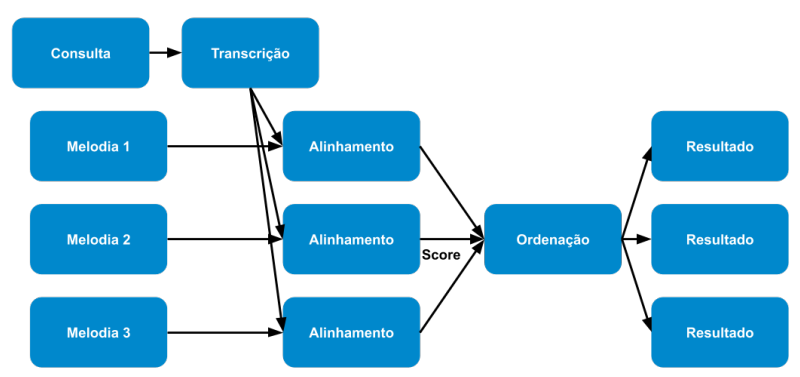

Figura 3.4: O alinhamento é feito entre a transcrição da consulta e as representações simbólicas das melodias.

Uma variação desse cenário utiliza apenas a sequência rítmica da melodia para realizar o alinhamento, ou seja, apenas os tempos e durações, sem considerar alturas para representar a melodia. Tal abordagem é por vezes chamada de query-by-tapping e é utilizada, por exemplo, na Musipedia ${ }^{1}$.

\subsubsection{Perfis de $F_{0}$}

Com o intuito de avaliar uma solução que utiliza vetores de $F_{0}$ e compara consultas com outras consultas, iremos converter cada consulta em uma representação vetorial comparável através de DTW a fim de medir a qualidade dos resultados obtidos. A representação desse esquema está na figura 3.5. Essa abordagem pode ser vista em Follow That Tune (Stasiak, 2014), que utiliza uma versão modificada do DTW para comparar cada query com os registros do banco. Salamon (Salamon et al., 2013a) usa uma representação especializada para a comparação melódica usando o algoritmo de alinhamento $Q_{\max }$.

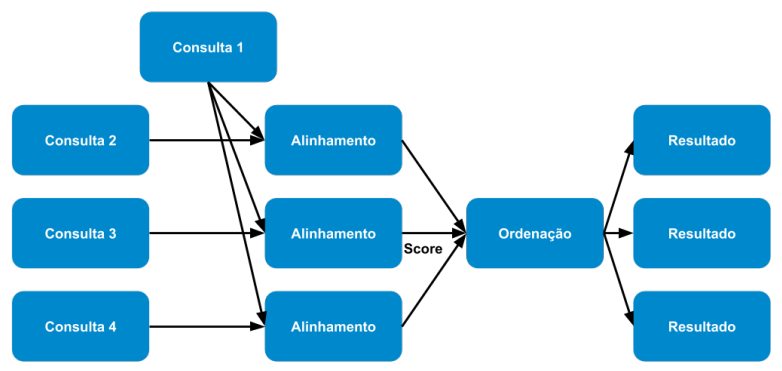

Figura 3.5: $O$ alinhamento é feito com a representação vetorial da consulta e as representações vetoriais das outras consultas armazenadas no banco.

Cada consulta do banco deve ser representada de uma forma que preserve as informações melódicas (altura e ritmo), mas que permita a comparação entre pitches a cada instante, relevando características de tonalidade e afinação da versão cantarolada. Uma opção, portanto, é utilizar uma representação de vetor de classes de alturas, que pode ser rotacionada 12 vezes para considerar cada possível transposição de tonalidade antes do alinhamento. Serão alinhadas assim as 12 rotações de cada vetor de classe de alturas com as consultas do banco para obtenção de um único score, que deve ser aquele que representa o menor custo de alinhamento. Isso permitirá ordenar os scores da consulta com cada gravação cantarolada do banco para gerar um ranking.

\footnotetext{
${ }^{1}$ https://www.musipedia.org/query_by_tapping.html
} 


\section{Capítulo 4}

\section{Experimentos e discussão}

Neste capítulo discutiremos a execução e os resultados dos experimentos realizados. Para facilitar a reprodução dos resultados, bem como permitir um melhor entendimento dos detalhes de implementação dos algoritmos empregados, todo o código utilizado está disponível no Github (Goródscy, 2019). As tabelas que veremos aqui são resumos dos resultados obtidos, sendo que as tabelas completas também estão disponíveis no Github, bem como a documentação de uso e um dockerfile para simular o ambiente em que os algoritmos foram executados. Os códigos foram implementados na maior parte em Python, mas têm uma pequena extensão em $\mathrm{C}$ e alguns scripts bash para automatizar tarefas. Além do código do experimento, há um tutorial utilizando Jupyter Notebook, demonstrando passo a passo cada experimento descrito aqui, também disponível no Github

\subsection{Banco de dados}

O banco de dados que foi utilizado nos experimentos deste trabalho, e que está de acordo com o descrito na metodologia, é fornecido na competição anual de QBH do MIREX (Music Information Retrieval Evaluation eXchange). Ele é composto por 48 melodias distintas, e cada melodia é cantarolada por 195 pessoas, tendo sido feita a gravação ao longo de um período de 7 anos, totalizando 4431 consultas distintas. As melodias presentes no banco têm uma representação simbólica MIDI, monofônica, que representa completamente cada melodia, identificada por um chave/ID inteira. As consultas cantaroladas estão armazenadas em arquivos WAV e estão associadas ao ano de gravação, ao identificador da pessoa que realizou a gravação e ao identificador da melodia que aquela gravação representa. As consultas cantaroladas começam sempre a partir do início da melodia, assim como aparece na representação simbólica e tem uma duração comum de 10 segundos. Como cada indivíduo utiliza um andamento ligeiramente diferente dos outros e a duração da gravação é sempre a mesma, a porcentagem da melodia coberta pela gravação varia de consulta a consulta. Isso traz consequências ao algoritmo de alinhamento, pois ele pode considerar que o trecho inicial será sempre o mesmo, apenas o fim da sequência é desconhecido. Isso simplifica o problema em relação a possíveis consultas que começassem em qualquer ponto da melodia e tivessem também uma duração arbitrária.

\subsection{Ferramenta existente: Soundhound}

A ferramenta utilizada neste cenário, que seguia os requisitos da metodologia descrita, é o Soundhound. O Soundhound é uma plataforma aberta para envio de gravações, que retorna títulos de músicas para cada consulta realizada. O Soundhound utiliza a estratégia de alinhamento de consulta contra consulta (MIREX, 2017), assim como o experimento na seção 4.4. Isso quer dizer que o Soundhound possui uma lista de consultas já armazenadas e classificadas, e utiliza essa base para gerar um ranking e tentar classificar novas consultas realizadas. Ele funcionou com uma interface web enquanto era conhecido como Midomi, e hoje disponibiliza aplicativos que podem ser baixados gratuitamente em dispositivos móveis com Android e IOS. As consultas são gravadas 


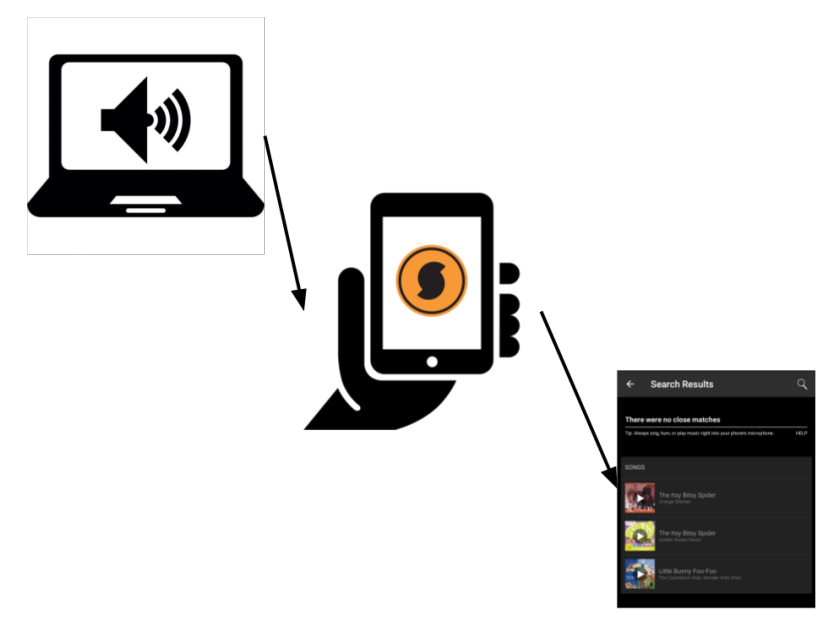

Figura 4.1: Processo de execução do experimento.

através do microfone do dispositivo e enviadas ao servidor da ferramenta, que alinha a consulta com a base de conhecimento que possui, devolvendo uma lista de possíveis respostas por ordem da similaridade aferida por seus modelos (não divulgados). O Soundhound possui código fechado, portanto não atende a todos os requisitos propostos na metodologia.

O Soundhound também não disponibiliza a lista de títulos que ele possui em sua base de conhecimento, apesar de termos especificado que isso seria importante para a metodologia. Porém, foi possível realizar um levantamento das melodias que a plataforma reconhece, dentre aquelas que estão no nosso banco de consultas cantaroladas. Para tal, foram enviadas consultas do banco para o Soundhound, para registrar quais consultas retornavam algum resultado correto. Para cada melodia, se o Soundhound encontrasse pelo menos 1 resultado correto, em qualquer consulta cantarolada relativa àquela melodia, concluímos que a melodia faz parte de sua base de conhecimento.

Esse trabalho foi realizado manualmente e de forma laboriosa, visto que o Soundhound devolve uma lista de títulos, e o nosso banco de consultas possui apenas um número de identificação da melodia; isso tornou necessário em vários casos a checagem através do vídeo associado para decidir se a resposta estava associada à melodia esperada. Fazíamos até 5 tentativas de identificação de cada melodia, e caso não fosse reconhecida, aceitávamos que a ferramenta não possuía a melodia na base. Ao todo 29 melodias (dentre as 48) foram identificadas pelo Soundhound, ou seja algo próximo de $60 \%$ das melodias. A lista das melodias reconhecidas através desse processo é exibida na tabela 4.3. Podemos ver na tabela que alguns dos identificadores estão associados a mais de um título no banco do Soundhound. Isso significa que o Soundhound possui mais de uma versão de uma mesma melodia, às vezes com uma instrumentação diferente, outras vezes em idiomas diferentes.

A comunicação do sistema com o banco também não corresponde ao prescrito na metodologia, pois a plataforma não possuía uma interface aberta para envio das consultas em lote, tornando necessário o envio manual de cada consulta testada no Soundhound através do microfone do celular, como exibido na figura 4.1. Isso traz desvantagens, como a adição do som ambiente à gravação enviada ao sistema, e o uso de tempo muito maior para a realização do experimento. Por conta disso, selecionamos um subconjunto de consultas para realizar o experimento, usando as 29 melodias conhecidas pela ferramenta, mas com um limitador de 10 consultas por melodia, totalizando 290 consultas, a fim de obter um bom panorama sobre o comportamento do sistema avaliado. Enviamos além disso a totalidade das consultas referentes às melodias 1, 2, 7 e 8, para mapear com maior detalhamento algumas características dos resultados observados em casos específicos. Para cada consulta enviada foi anotada sua posição no ranking devolvido, e a informação de falha em produzir o resultado correto, caso ocorresse.

Na melodia 1, Alouette, houve uma grande confusão pelo Soundhound com a melodia 43, Itsy bitsy spider, como pode ser verificado na tabela 4.2. A confusão é compreensível, já que as duas melodias possuem um trecho onde a sequência de pitches e o ritmo são idênticos, como visto na 


\begin{tabular}{|c|c|}
\hline Identificador & Título \\
\hline 1 & Alouette \\
\hline 2 & I've been working on the railroad \\
\hline 7 & Skip to my lou \\
\hline 8 & Farmer in the dell \\
\hline 9 & Buffalo gals \\
\hline 10 & Yankee doodle \\
\hline 11 & Ten little indians \\
\hline 13 & 小毛驴 \\
\hline 14 & Twinkle twinkle little star \\
\hline 15 & Little brown jug \\
\hline 17 & ゆかいな牧/ Old macdonald \\
\hline 18 & 世上只有妈妈好 \\
\hline 20 & Happy birthday \\
\hline 22 & Two tigers \\
\hline 23 & 明天会更好 \\
\hline 24 & 泥娃娃 \\
\hline 26 & 长城谣 \\
\hline 27 & 青春舞曲 \\
\hline 29 & Mo li hua \\
\hline 30 & London bridge is falling down \\
\hline 33 & 高山青 \\
\hline 36 & 苏珊娜/ Oh susanna \\
\hline 37 & 童年 \\
\hline 38 & 萍聚 \\
\hline 41 & I love you \\
\hline 42 & 泼水歌 \\
\hline 43 & Itsy bitsy spider \\
\hline 44 & 蜗牛与黄㛤鸟 \\
\hline 45 & 泼水歌 \\
\hline
\end{tabular}

Tabela 4.1: Lista dos títulos encontrados pelo Soundhound, com o respectivo identificador utilizado para a melodia no banco de dados do MIREX.

figura 4.2. Apesar disso, como as melodias possuem desfechos diferentes não as consideramos idênticas. O Soundhound retornou $21.05 \%$ das vezes a melodia 1 e $26.31 \%$ a melodia 43 . Em $52.63 \%$ das vezes o Soundhound não retornou qualquer resposta que fizesse sentido, um valor relativamente alto se comparado com outras melodias. Entre as consultas identificadas como referentes à melodia Alouette, havia uma gravação com conteúdo incorreto, um erro de classificação no banco que foi identificado manualmente. Não identificamos em nenhuma outra consulta algo semelhante, mas a hipótese de existência de outros erros de classificação não pode ser descartada. No geral, o Soundhound obteve índices de acerto abaixo de $90 \%$, com média de $70.38 \%$ e MRR de $66.65 \%$, como pode ser visto na tabela 4.3.

De forma geral, o Soundhound parece funcionar bem para as melodias que ele conhece. Para permitir resultado semelhante, uma ferramenta de QBH deve possuir um grande número de gravações cantaroladas já classificadas e armazenadas no banco de dados. Esse é um dos problemas dessa abordagem, de query $\times$ query, pois é custoso obter uma grande quantidade de consultas já classificadas e rotuladas, e sem isso o problema de alinhamento de sequências melódicas se torna muito mais difícil. O que chama a atenção é o tamanho do banco que o Soundhound parece possuir, e que, apesar do tamanho e por conta da eficiência do algoritmo, consegue retornar rapidamente respostas precisas. Um detalhe que causa prejuízo para o experimento é que o Soundhound por 


\begin{tabular}{|c|c|c|}
\hline Consulta & $1-$ Alouette & $43-$ Itsy bitsy spider \\
\hline 1 & $\mathrm{x}$ & $\mathrm{x}$ \\
\hline 2 & & $\mathrm{x}$ \\
\hline 3 & & $\mathrm{x}$ \\
\hline 4 & & \\
\hline 5 & & \\
\hline 6 & & \\
\hline 7 & & \\
\hline 8 & & \\
\hline 9 & & \\
\hline 10 & & \\
\hline 11 & $\mathrm{x}$ & \\
\hline 12 & $\mathrm{x}$ & \\
\hline 13 & & \\
\hline 14 & & \\
\hline 15 & & \\
\hline 16 & $\mathrm{x}$ & \\
\hline 17 & & \\
\hline 18 & & \\
\hline 19 & & \\
\hline Média & $21.05 \%$ & \\
\hline
\end{tabular}

Tabela 4.2: Lista de resultados do Soundhound para consultas referentes à melodia 1 - Alouette

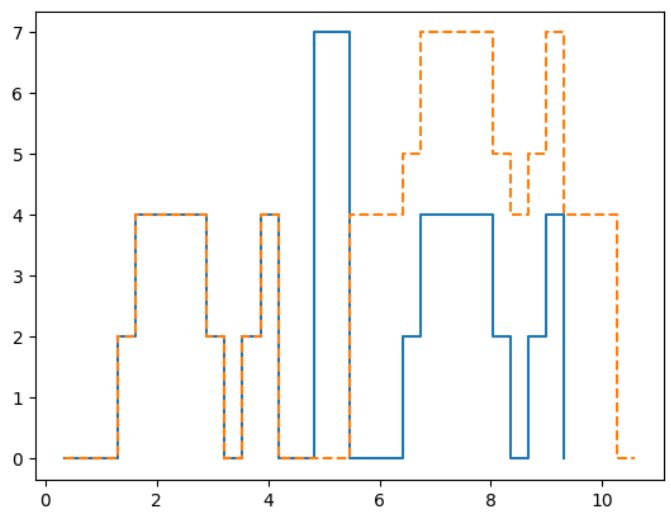

Figura 4.2: Trecho das melodias 1 - Alouette (azul) e 43 - Itsy bitsy spider (laranja) em sequências de classes de alturas.

vezes retornava resultados diferentes para a mesma consulta, mesmo sendo as consultas repetidas com o mesmo volume e no mesmo ambiente. Considerando este cenário, é bastante curioso esse tipo de comportamento, sugerindo a existência de um fator de aleatoriedade em seu algoritmo. Este experimento não é suficiente para comprovar as conclusões a que chegamos, já que usamos uma quantidade bem limitada de consultas. Porém, é possível ter uma ideia panorâmica e discutir pontos positivos e negativos que podem ser identificados na ferramenta a partir de uma abordagem empírica, e assim definir as metas e expectativas para os experimentos seguintes. Os resultados anotados de cada consulta enviada ao Soundhound podem ser vistos no arquivo soundhound.xlsx encontrado no Github. 


\begin{tabular}{|c|c|c|}
\hline Melodia & Média de acertos & MRR \\
\hline 1 & $21.05 \%$ & $21.05 \%$ \\
\hline 2 & $64.29 \%$ & $64.29 \%$ \\
\hline 7 & $86.67 \%$ & $86.67 \%$ \\
\hline 8 & $86.67 \%$ & $86.67 \%$ \\
\hline 9 & $70 \%$ & $60 \%$ \\
\hline 10 & $100 \%$ & $100 \%$ \\
\hline 11 & $80 \%$ & $58.33 \%$ \\
\hline 13 & $70 \%$ & $60 \%$ \\
\hline 14 & $80 \%$ & $80 \%$ \\
\hline 15 & $70 \%$ & $65 \%$ \\
\hline 17 & $50 \%$ & $45 \%$ \\
\hline 18 & $80 \%$ & $80 \%$ \\
\hline 20 & $70 \%$ & $65 \%$ \\
\hline 22 & $70 \%$ & $55 \%$ \\
\hline 23 & $60 \%$ & $60 \%$ \\
\hline 24 & $30 \%$ & $30 \%$ \\
\hline 26 & $70 \%$ & $70 \%$ \\
\hline 27 & $80 \%$ & $80 \%$ \\
\hline 29 & $80 \%$ & $80 \%$ \\
\hline 30 & $100 \%$ & $95 \%$ \\
\hline 33 & $50 \%$ & $50 \%$ \\
\hline 36 & $80 \%$ & $80 \%$ \\
\hline 37 & $100 \%$ & $95 \%$ \\
\hline 38 & $80 \%$ & $80 \%$ \\
\hline 41 & $90 \%$ & $80 \%$ \\
\hline 42 & $70 \%$ & $70 \%$ \\
\hline 43 & $40 \%$ & $23.33 \%$ \\
\hline 44 & $80 \%$ & $75 \%$ \\
\hline 45 & $60 \%$ & $60 \%$ \\
\hline Geral & $70.28 \%$ & $66.66 \%$ \\
\hline
\end{tabular}

Tabela 4.3: Lista geral de resultados do Soundhound, agrupados por melodia

\subsection{Recuperação via sequências melódicas (alturas e durações)}

Neste experimento usamos um banco de dados com representações simbólicas e comparamos transcrições das consultas para criar o ranking das respostas. As representações das 48 melodias foram somadas às 5944 representações do banco de MIDIs Essen ${ }^{1}$, para aumentar a dificuldade de acertar a resposta correta por acaso. Ao todo ficamos com 5992 melodias. Para converter as consultas em áudio para sequências de alturas, utilizamos e comparamos 2 sistemas de transcrição, Melodia (Salamon e Gómez, 2012) e ASyMuT (Mitre e Queiroz, 2005), a fim de averiguar se alguma ferramenta traz vantagens ao processo da alinhamento e busca. Para o alinhamento, utilizaremos uma versão reproduzida do SMBGT (Kotsifakos et al., 2011), que produz resultados muito bons de acordo com o artigo original, e que possui exatamente o mesmo cenário dos nossos experimentos, e uma implementação do DTW, disponível na biblioteca de processamento de áudio em Python, Librosa $^{2}$. Para os dados deste experimento, utilizamos as representações MIDI presentes no banco e as consultas cantaroladas diretamente em áudio. As consultas são transcritas para uma representação

\footnotetext{
${ }^{1}$ http://www.esac-data.org

${ }^{2}$ https://librosa.github.io/librosa/
} 
compatível com MIDI para depois extrairmos a sequência melódica.

O ASyMuT (Mitre e Queiroz, 2005), cujo código e documentação estão disponíveis no GitHub ${ }^{3}$, realiza a transcrição produzindo listas de candidatos a F0 a partir da análise do espectro do sinal, e escolhe o candidato que maximiza a soma das energias na série harmônica correspondente. Finalmente, o sistema produz uma sequência de pitches que passa por um processo de arredondamento (para a escala cromática) e agrupamento em eventos MIDI. O ASyMuT possui uma diversidade de parâmetros de configuração, tais como faixa de frequências procuradas, tamanho da janela de análise e intervalo entre janelas (hop size), entre outros. A documentação do sistema discute mais precisamente a utilização dos parâmetros.

O processo de transcrição do Melodia (Salamon e Gómez, 2012) é feito em três passos, sendo o primeiro um arredondamento dos valores de frequência fundamental (que estavam em valores float de MIDI) para o valor inteiro mais próximo, o segundo passo é feito com um filtro da mediana sobre o vetor arredondado, e o terceiro passo descarta saltos melódicos considerados improváveis na evolução temporal dos pitches a fim de produzir eventos MIDI.

$\mathrm{Na}$ figura 4.3a podemos ver os resultados da extração de frequência fundamental e da representação MIDI criados com o algoritmo Melodia online ${ }^{4}$, disponibilizado por seu criador. O primeiro passo (arredondamento) gera a visualização mostrada na figura 4.3b. O filtro da mediana (segundo passo) elimina eventos de duração muito curta que aparecem por causa dos arredondamentos de valores de F0 que oscilam entre dois semitons adjacentes, como se pode ver na figura $4.3 \mathrm{c}$. Por fim, o terceiro passo (suavização) procura trechos de estabilidade, ou seja, regiões na curva de pitches produzida em que não ocorrem trocas de nota. Os trechos encontrados que têm duração maior que um certo limiar serão convertidos em um evento MIDI, gerando o resultado observado na figura 4.3a.

O Melodia aceita como parâmetros de configuração a faixa de frequências de busca e um parâmetro de limiar de detecção de vozes, que controla a sensibilidade do algoritmo para encontrar frequências fundamentais (um valor muito alto desse parâmetro pode causar a detecção de F0 onde existe apenas silêncio ou sons sem frequência fundamental definida), além de um parâmetro de suavização, que é o tamanho do filtro da mediana utilizado no passo 2. Na figura 4.3a, o filtro da mediana foi configurado para usar aproximadamente $100 \mathrm{~ms}$, que resulta em 35 frames de $2.9 \mathrm{~ms}$ (o valor default usado pelo Melodia). O limiar de duração de eventos também foi definido em 100ms, a fim de eliminar detecções espúrias de eventos muito curtos; a definição de um valor apropriado para esse parâmetro é muito dependente do contexto: nesse exemplo o algoritmo ainda detectou eventos espúrios com duração de $110 \mathrm{~ms}$, porém existem eventos legítimos com duração de apenas 130 ms. A conversão da curva de pitches em uma sequência de eventos discretos é o passo mais problemático, e grande parte dos erros de transcrição vêm por causa dele. Um processo comum para realização dessa tarefa é a aplicação de um filtro digital para reduzir a flutuação do sinal em janelas próximas. Porém, escolher o filtro e o valor adequado de seus parâmetros é a grande dificuldade, e normalmente não há receita de bolo que funcione em qualquer cenário.

Para este experimento, utilizamos o SMBGT e o DTW como algoritmos de alinhamento. O SMBGT foi reproduzido da forma como descrito na seção 2.2.2, e o DTW é aplicado com a implementação existente no Librosa (lembrando que todos os códigos estão no github (Goródscy, 2019)). Os resultados estão na tabela 4.4.

Os resultados que vemos aqui ficam muito aquém dos $90 \%$ que esperávamos, portanto consideramos o desempenho dessa técnica, baseada em representações de sequências de alturas, bastante insatisfatória. Com o DTW, os resultados ficam ainda piores, sendo o tempo de execução do experimento consideravelmente maior. Utilizando exclusivamente a informação rítmica também, observamos um desempenho igualmente insatisfatório, sugerindo que essas representações se mostram pouco promissoras.

Outro problema desse experimento, causado pela grande quantidade de parâmetros, tanto no algoritmo de transcrição, quanto no algoritmo de alinhamento, é a dificuldade em otimizar o setup experimental para o experimento como um todo. Podemos ver um exemplo do resultado da alteração

\footnotetext{
${ }^{3}$ https://github.com/adrianomitre/asymut

${ }^{4}$ https://github.com/justinsalamon/audio_to_midi_melodia
} 


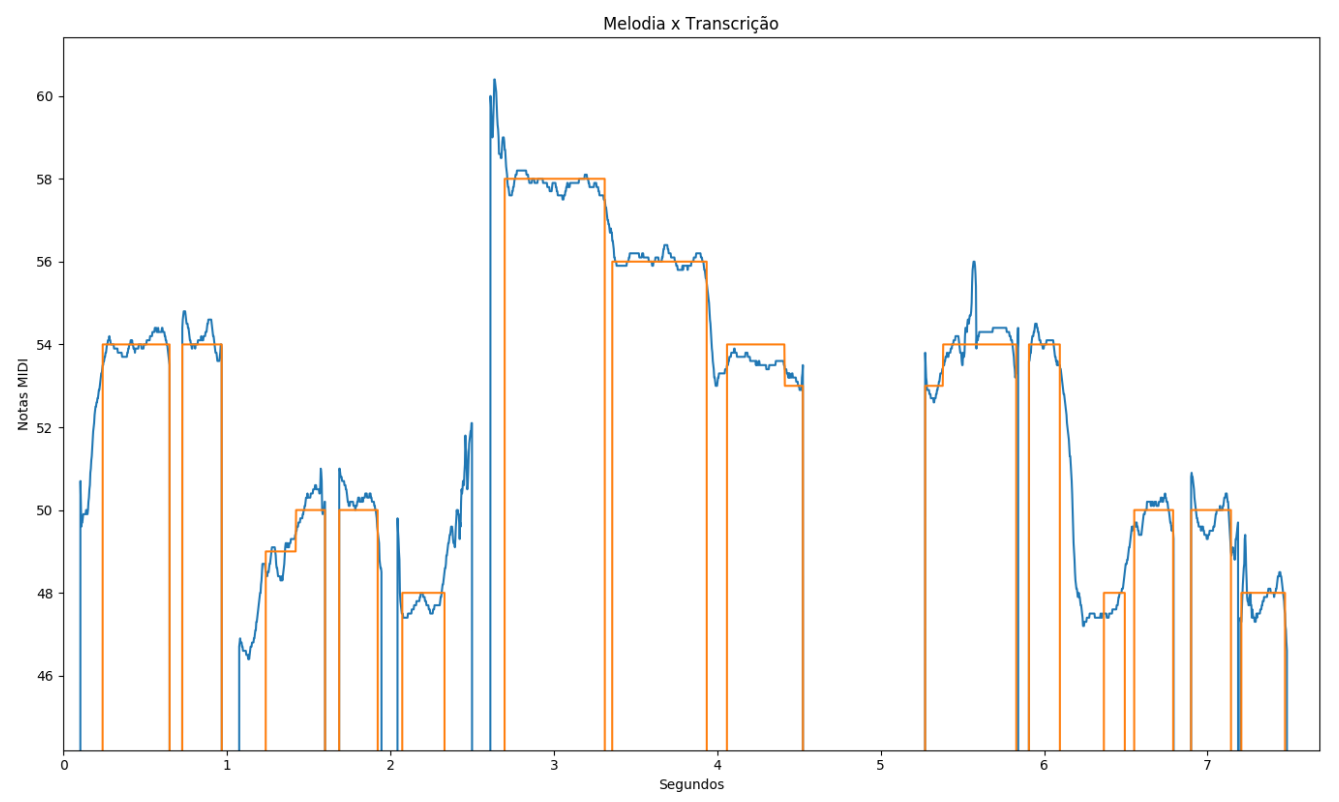

(a) Frequências fundamentais e transcrição.

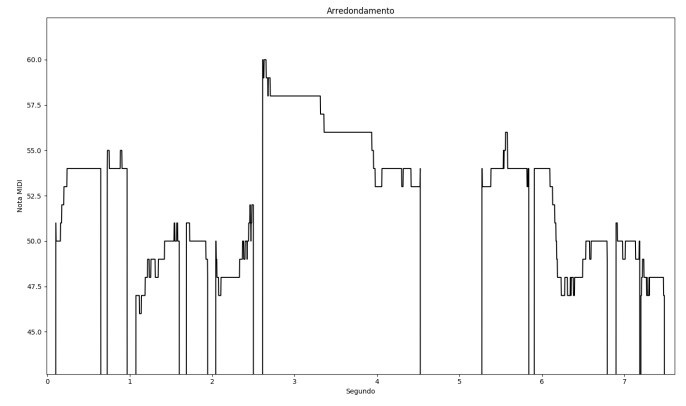

(b) Arredondamento.

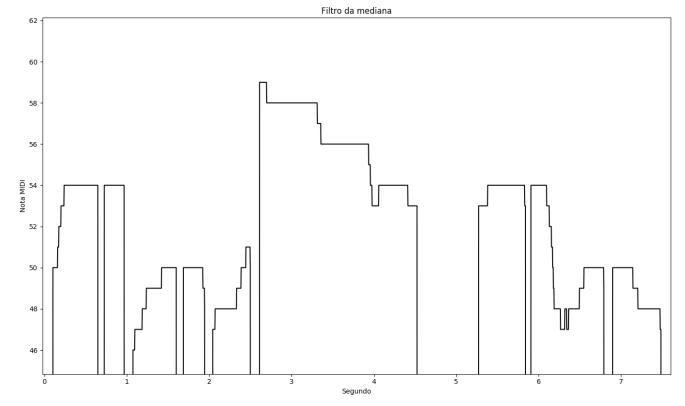

(c) Mediana.

Figura 4.3: Algoritmo de transcrição que utiliza o Melodia.

dos parâmetros na tabela 4.5. Além disso, esse valor ótimo provavelmente seria diferente dependendo do banco de dados utilizado (lembrando que nesse experimento o banco incluia $99.2 \%$ de músicas não relacionadas com as buscas). Os códigos para reproduzir este experimento se encontram em code/pitch no Github. O tutorial está em notebooks/pitch.

\subsection{Recuperação via perfis de F0}

O banco de dados é composto pelas 4431 consultas disponíveis no MIREX, já que neste cenário iremos comparar as consultas com outras consultas disponíveis no banco, à maneira do que faz o sistema Soundhound. O banco de dados do MIREX já possuía um vetor de perfil de pitches associado a cada consulta cantarolada, então, para esse experimento, decidimos não efetuar a transcrição do áudio e apenas utilizar o perfil de F0 existente. Um exemplo de perfil de F0 presente no banco pode ser visto na figura 4.4a. Também foi aplicado um redimensionamento no vetor, que possuía 250 elementos $^{5}$, para produzir representações com 40 elementos, como ilustrado na figura 4.4c. Esse

\footnotetext{
${ }^{5}$ obtidos a partir da gravação de 10 segundos com taxa de amostragem de $8000 \mathrm{~Hz}$, usando janelas de $40 \mathrm{~ms}$ ou 320 amostras.
} 


\begin{tabular}{|l|l|l|l|l|l|}
\hline Transcrição & Alinhamento & Descritor & Recall & MRR & Posição média \\
\hline ASyMuT & SMBGT & Intervalo & $32 \%$ & $19 \%$ & 5 \\
\hline Melodia & SMBGT & Intervalo & $32 \%$ & $23 \%$ & 4 \\
\hline ASyMuT & DTW & Intervalo & $3.25 \%$ & $1.53 \%$ & 65 \\
\hline Melodia & DTW & Intervalo & $11.67 \%$ & $5.2 \%$ & 19 \\
\hline ASyMuT & SMBGT & Onset & $0.16 \%$ & $0.05 \%$ & 2000 \\
\hline Melodia & SMBGT & Onset & $6.36 \%$ & $1.13 \%$ & 88 \\
\hline ASyMuT & DTW & Onset & $0.16 \%$ & $0.05 \%$ & 2000 \\
\hline Melodia & DTW & Onset & $0.04 \%$ & $0 \%$ & - \\
\hline
\end{tabular}

Tabela 4.4: Resultados para as buscas usando sequências melódicas, em função do sistema de transcrição (ASyMuT e Melodia), técnica de alinhamento (SMBGT e DTW) e representação (intervalos de alturas e onsets).

\begin{tabular}{|l|l|l|l|l|l|}
\hline & Min. dur. & Smooth & Recall & MRR & Posição média \\
\hline \multirow{5}{*}{ Melodia } & 0.1 & 0.0 & $4 \%$ & $2 \%$ & 38 \\
& 0.05 & 0.0 & $32 \%$ & $23 \%$ & 4 \\
& 0.01 & 0.0 & $4 \%$ & $1 \%$ & 80 \\
& 0.001 & 1.0 & $6 \%$ & $2 \%$ & 84 \\
\hline & Tam. Janela & Hop Size & Recall & MRR & Posição média \\
\hline \multirow{5}{*}{ ASyMuT } & 512 & 64 & $32 \%$ & $19 \%$ & 5 \\
& 512 & 128 & $29 \%$ & $17 \%$ & 5 \\
& 512 & 256 & $23 \%$ & $13 \%$ & 7 \\
& 1024 & 256 & $13 \%$ & $6 \%$ & 16 \\
\hline
\end{tabular}

Tabela 4.5: Resultado da alteração dos parâmetros no algoritmo de transcrição.

passo é importante porque os algoritmos de alinhamento são quadráticos no tamanho dos vetores, e os experimentos com as representações originais não seria exequível em tempo hábil.

$\mathrm{O}$ vetor de frequências fundamentais foi alterado para possibilitar a comparação invariante por oitava em que a consulta foi cantarolada, aplicando-se o mod12 sobre os valores de pitch, visto na figura 4.4b. Além dessa alteração também foi utilizada uma técnica de reafinação que produziu melhorias no desempenho. Essa técnica calcula primeiramente o valor médio residual, para uma sequência de classes de alturas $\mathrm{S}$, pela seguinte fórmula:

$$
r=\frac{1}{N} * \sum_{i=1}^{N} S_{i}-\operatorname{int}\left(S_{i}\right) .
$$

Esse resíduo é então subtraído de cada posição da sequência S:

$$
A_{i}=\bmod \left(S_{i}-r, 12\right) \text {. }
$$

A representação assim obtida é uma sequência de classes de alturas inteiras com resíduo médio igual a 0 , o que permite representar corretamente sequências melódicas com intervalos afinados. Finalmente, para permitir a comparação entre sequências melódicas cantadas corretamente em tonalidades diferentes, cada consulta é transposta 12 vezes, uma para cada tonalidade possível, antes de ser alinhada com o banco de dados. O resultado das transposições está ilustrado na figura 4.4d. Cada transposição de uma consulta era então comparada com cada elemento do banco, e o score final é definido como o menor valor encontrado entre qualquer uma das transposições.

Para o alinhamento foi utilizada a implementação do DTW disponível na biblioteca Librosa ${ }^{6}$.

\footnotetext{
${ }^{6}$ https://librosa.github.io/librosa/
} 

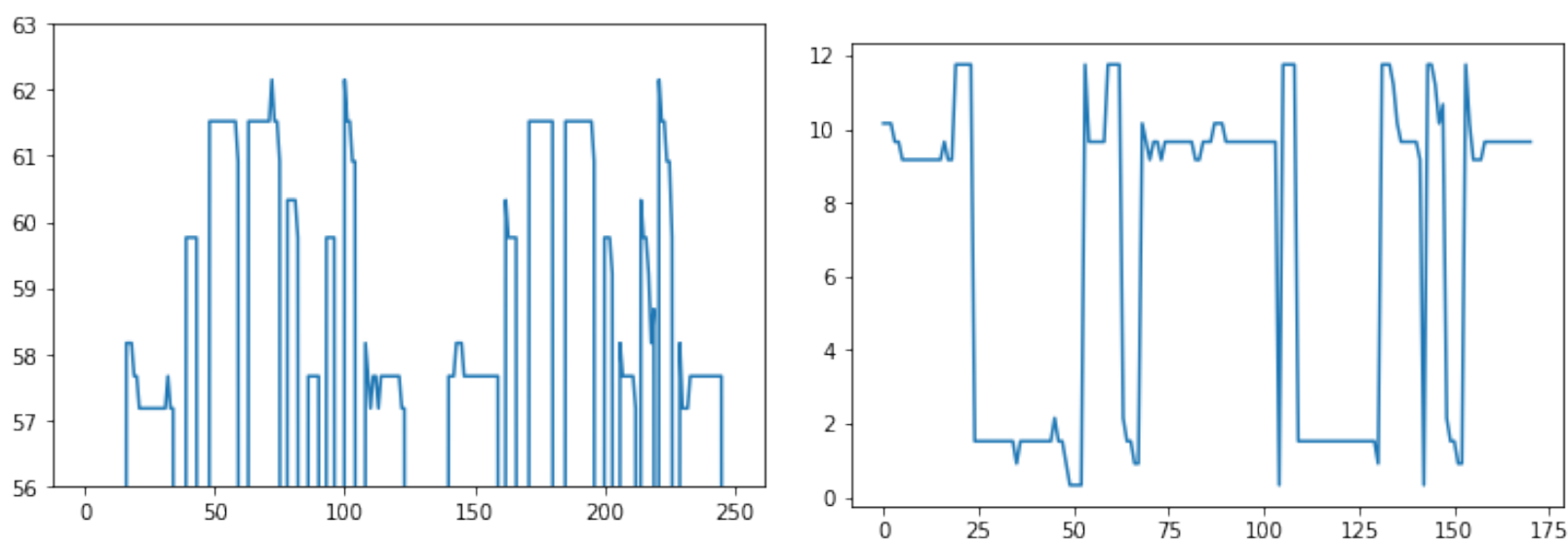

(a) Vetor de pitches de uma gravação cantarolada representando a melodia 1, como presente no banco do MIREX.

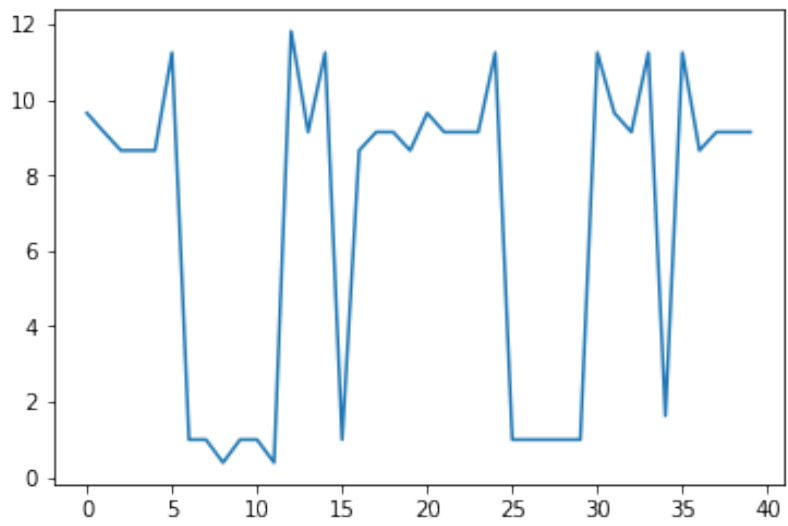

(c) Vetor de classes de alturas reduzido. (b) Vetor de classes de alturas, gerado com a aplicação de Mod12 no vetor de pitches.

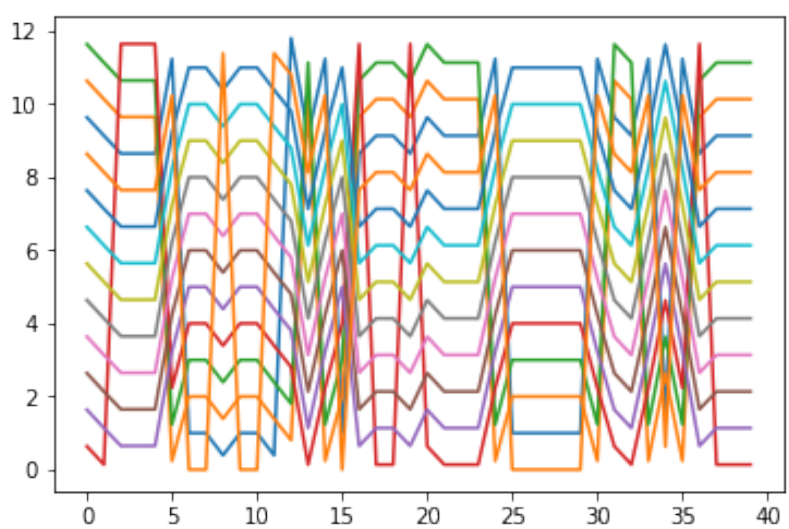

(d) Transposições do vetor.

Figura 4.4: Passos de processamento neste experimento.

As consultas começam todas a partir de um mesmo ponto na melodia, mas terminam em pontos diferentes, já que as gravações têm a mesma duração mas andamentos diferentes. Por isso, a matriz de distâncias acumuladas devolvida pela ferramenta foi alterada para possibilitar a comparação de alinhamentos que terminam antes do final de um dos dois vetores (consulta e elemento do banco de dados), através de um peso proporcional multiplicado em cada posição da matriz. A solução de multiplicação de pesos para calcular o score de um alinhamento foi proposta em substituição de um método preliminar que considerava apenas alinhamentos que terminassem na última linha da matriz de custo acumulado, forçando que as consultas fossem inteiramente alinhadas com qualquer elemento do banco de dados, o que inseria custos espúrios e imprevisíveis de alinhamento devido à diferença de cobertura melódica das gravações. Na tabela 4.6 observa-se a melhoria no desempenho pelo ajuste de afinação e pelo uso dos pesos na matriz de custos acumulados.

Após realizar o alinhamento da consulta com cada elemento do banco, um ranking é criado, a partir dos valores de score definidos a partir das matrizes de distâncias acumuladas. Identificamos a existência de várias possibilidades de classificação para criação desse ranking, que afetam a qualidade dos resultados. O mais simples é o modelo topN, que consiste em formar uma lista com os $\mathrm{N}$ maiores resultados usando os próprios valores da distância DTW (em ordem decrescente):

$$
\text { score }_{n}=\text { scoreDTW }_{n} .
$$

O modelo de classes tira a média dos scores obtidos com o alinhamento da consulta com cada gravação de uma mesma classe (todas as demais gravações da mesma melodia), e cria o ranking das médias dos scores por classe. Assim se a classe/melodia $m$ possui gravações $n_{1}, n_{2}, \ldots, n_{N}$, com 


\begin{tabular}{|c|c|c|c|}
\hline & original & com reafinação & com reafinação+peso \\
\hline MRR & $71 \%$ & $73 \%$ & $87 \%$ \\
\hline Recall & $84 \%$ & $84 \%$ & $94 \%$ \\
\hline
\end{tabular}

Tabela 4.6: Valores para diferentes melhorias utilizando as consultas da melodia 1.

scores respectivos score $_{n_{1}}$, score $_{n_{2}}, \ldots$, score $_{n_{N}}$ então o score da classe será

$$
\text { scoreClasse }_{m}=\frac{1}{N} * \sum_{i=1}^{N} \text { score }_{n_{i}} .
$$

Os outros 3 modelos consideram os resultados dos modelos anteriores, através de combinações diferentes de seus rankings. No caso do modelo inter, o ranking final é um subconjunto do ranking do modelo topN, considerando apenas as gravações com os 3 maiores scores no modelo de classes. O score final do alinhamento no caso do modelo mult é o produto do score do DTW pelo respectivo score médio da classe. No caso do modelo mult2 o peso da classe é aumentado tomando-se os quadrados dos valores:

$$
\begin{gathered}
\text { scoreMult }_{n}=\text { scoreDTW }_{n} * \text { scoreClasse }_{m} \\
\text { scoreMult }_{n}=\text { scoreDTW }_{n} * \text { scoreClasse }_{m}^{2} .
\end{gathered}
$$

Para cada uma das técnicas de ranking, produzimos uma lista com as 5 gravações de maior score utilizando a fórmula correspondente (resultados corretos que aparecem após a $5 \underline{a}$ posição são equivalentes a melodias não encontradas no banco).

Na tabela 4.7 vemos, para cada consulta da melodia 1, qual o resultado MRR da aplicação de cada modelo de ranking. Dentre os resultados dos modelos para essa melodia, vemos que a consulta 19 não era encontrada em nenhum modelo; essa consulta se refere à gravação classificada incorretamente, e que por isso não poderia ser classificada como correspondente à melodia 1. Vemos que na maior parte das consultas, a melodia que é encontrada em primeira posição em um modelo também será encontrada nos outros. O modelo mult foi o que obteve o pior desempenho para essa melodia, enquanto todos os outros tiveram um recall igual, não tendo acertado apenas a consulta classificada incorretamente. Porém, um fato interessante é que no modelo inter o MRR está significativamente mais alto, pois este modelo quase sempre colocou a resposta correta na primeira posição (a única exceção foi a consulta 2).

$\mathrm{Na}$ tabela 4.8 exibimos os resultados por melodia para o modelo de ranking top5. Uma característica que conseguimos perceber nessa tabela é que o número de gravações cantaroladas de uma mesma melodia no banco pode afetar a lista de respostas para as consultas, já que as melodias com mais registros no banco possuem porcentagem de acerto maior. Isso pode ocorrer basicamente por 2 motivos: porque seria mais difícil acertar uma melodia ao acaso se ela possui uma quantidade reduzida de exemplos em comparação com as outras classes, e porque um número maior de indivíduos cantarolando a mesma melodia de maneiras (e com erros) diferentes facilitaria encontrar algum exemplo mais parecido com aquele da consulta.

Na tabela 4.9 vemos os resultados gerais, organizados por modelo de classificação. O modelo que obteve o melhor desempenho foi o mult2, mas a diferença entre os desempenhos no geral foi pequena e possivelmente qualquer um dos modelos poderia ser utilizado sem grandes prejuízos. Mas é interessante notar que, enquanto na melodia 1 o modelo inter teve o melhor MRR, essa tendência não se manteve no caso geral, sendo o modelo inter aquele com o pior valor de MRR geral e, além disso, o pior valor de recall. É interessante observar o fato que o modelo de classificação com o melhor MRR foi o mult2, porém, o modelo de classes e o top5 tiveram o recall em $97 \%$, o que mostra que ele possuía a resposta na lista em mais casos, apesar de estarem em posições mais baixas. Os resultados estão todos acima do limiar de $90 \%$ previsto na metodologia, o que consideramos satisfatório.

Por outro lado, este modelo de classificação é computacionalmente mais custoso do que o ali- 


\begin{tabular}{|c|c|c|c|c|c|}
\hline consulta & top5 & classes & inter & mult & mult2 \\
\hline 1 & 1.0 & 1.0 & 1.0 & 1.0 & 1.0 \\
\hline 2 & 0.5 & 0.5 & 0.5 & 0.0 & 0.2 \\
\hline 3 & 1.0 & 1.0 & 1.0 & 1.0 & 1.0 \\
\hline 4 & 1.0 & 1.0 & 1.0 & 1.0 & 1.0 \\
\hline 5 & 1.0 & 1.0 & 1.0 & 1.0 & 1.0 \\
\hline 6 & 1.0 & 1.0 & 1.0 & 1.0 & 1.0 \\
\hline 7 & 1.0 & 1.0 & 1.0 & 1.0 & 1.0 \\
\hline 8 & 1.0 & 1.0 & 1.0 & 1.0 & 1.0 \\
\hline 9 & 1.0 & 1.0 & 1.0 & 1.0 & 1.0 \\
\hline 10 & 1.0 & 1.0 & 1.0 & 1.0 & 1.0 \\
\hline 11 & 1.0 & 0.5 & 1.0 & 0.0 & 0.2 \\
\hline 12 & 0.5 & 0.5 & 1.0 & 1.0 & 1.0 \\
\hline 13 & 0.5 & 0.5 & 1.0 & 0.2 & 1.0 \\
\hline 14 & 1.0 & 0.5 & 1.0 & 1.0 & 1.0 \\
\hline 15 & 1.0 & 1.0 & 1.0 & 1.0 & 1.0 \\
\hline 16 & 1.0 & 1.0 & 1.0 & 1.0 & 1.0 \\
\hline 17 & 1.0 & 1.0 & 1.0 & 1.0 & 1.0 \\
\hline 18 & 1.0 & 1.0 & 1.0 & 1.0 & 1.0 \\
\hline 19 & 0.0 & 0.0 & 0.0 & 0.0 & 0.0 \\
\hline MRR & $87 \%$ & $82 \%$ & $92 \%$ & $80 \%$ & $87 \%$ \\
\hline Recall & $94 \%$ & $94 \%$ & $94 \%$ & $84 \%$ & $94 \%$ \\
\hline Posição média & $1.15 \%$ & $1.22 \%$ & $1.09 \%$ & $1.25 \%$ & $1.15 \%$ \\
\hline
\end{tabular}

Tabela 4.7: Resultados de RR, MRR, Recall e posição média para diferentes formas de ranking utilizando as consultas da melodia 1 .

nhamento de sequências melódicas, pois usa representações de dimensão consideravelmente maior. Mesmo aplicando o DTW sobre um resumo do vetor de frequências, com 40 elementos ao invés dos 250 originais, computar os 12 alinhamentos para cada uma das 4430 consultas, ou seja, realizar 53160 alinhamentos, levava alguns minutos em um cluster (o servidor BrucutuIV do IME-USP ${ }^{7}$ ). Isso significa que para terminar todos os alinhamentos de todas as 4431 consultas do banco, eram necessários entre 15 e 30 dias de processamento ininterrupto, mesmo com processamento paralelo naquele cluster. Os códigos para reproduzir este experimento se encontram em code/qxq no Github. O tutorial está em notebooks/qxq.

\footnotetext{
${ }^{7} \mathrm{O}$ BrucutuIV possui 48 cores de $2.2 \mathrm{GHz}, 378 \mathrm{~GB}$ de memória RAM, mas não está dedicado à aplicação, sendo compartilhado entre dezenas de usuários.
} 


\begin{tabular}{|c|c|c|c|}
\hline Melodia & Recall & MRR & Número de registros \\
\hline 1 & $94 \%$ & $87 \%$ & 19 \\
\hline 2 & $78 \%$ & $71 \%$ & 14 \\
\hline 3 & $63 \%$ & $57 \%$ & 11 \\
\hline 4 & $80 \%$ & $72 \%$ & 15 \\
\hline 5 & $80 \%$ & $80 \%$ & 15 \\
\hline 6 & $66 \%$ & $48 \%$ & 12 \\
\hline 7 & $93 \%$ & $86 \%$ & 15 \\
\hline 8 & $66 \%$ & $48 \%$ & 15 \\
\hline 9 & $75 \%$ & $58 \%$ & 12 \\
\hline 10 & $94 \%$ & $92 \%$ & 19 \\
\hline 11 & $91 \%$ & $89 \%$ & 96 \\
\hline 12 & $98 \%$ & $97 \%$ & 153 \\
\hline 13 & $97 \%$ & $97 \%$ & 161 \\
\hline 14 & $96 \%$ & $89 \%$ & 159 \\
\hline 15 & $85 \%$ & $79 \%$ & 27 \\
\hline 16 & $98 \%$ & $98 \%$ & 160 \\
\hline 17 & $96 \%$ & $88 \%$ & 152 \\
\hline 18 & $98 \%$ & $98 \%$ & 164 \\
\hline 19 & $98 \%$ & $96 \%$ & 158 \\
\hline 20 & $98 \%$ & $97 \%$ & 170 \\
\hline 21 & $98 \%$ & $93 \%$ & 66 \\
\hline 22 & $98 \%$ & $94 \%$ & 172 \\
\hline 23 & $96 \%$ & $92 \%$ & 62 \\
\hline 24 & $94 \%$ & $92 \%$ & 121 \\
\hline 25 & $98 \%$ & $93 \%$ & 123 \\
\hline 26 & $94 \%$ & $91 \%$ & 52 \\
\hline 27 & $97 \%$ & $96 \%$ & 85 \\
\hline 28 & $96 \%$ & $95 \%$ & 91 \\
\hline 29 & $99 \%$ & $97 \%$ & 149 \\
\hline 30 & $99 \%$ & $98 \%$ & 144 \\
\hline 31 & $95 \%$ & $92 \%$ & 141 \\
\hline 32 & $98 \%$ & $97 \%$ & 137 \\
\hline 33 & $96 \%$ & $90 \%$ & 116 \\
\hline 34 & $97 \%$ & $97 \%$ & 137 \\
\hline 35 & $97 \%$ & $95 \%$ & 149 \\
\hline 36 & $97 \%$ & $85 \%$ & 43 \\
\hline 37 & $95 \%$ & $90 \%$ & 66 \\
\hline 38 & $95 \%$ & $93 \%$ & 114 \\
\hline 39 & $96 \%$ & $93 \%$ & 147 \\
\hline 40 & $92 \%$ & $93 \%$ & 71 \\
\hline 41 & $100 \%$ & $99 \%$ & 126 \\
\hline 42 & $94 \%$ & $93 \%$ & 92 \\
\hline 43 & $98 \%$ & $92 \%$ & 123 \\
\hline 44 & $92 \%$ & $89 \%$ & 80 \\
\hline 45 & $96 \%$ & $95 \%$ & 99 \\
\hline 46 & $95 \%$ & $92 \%$ & 92 \\
\hline 47 & $89 \%$ & $88 \%$ & 29 \\
\hline 48 & $96 \%$ & $94 \%$ & 53 \\
\hline
\end{tabular}

Tabela 4.8: Valores para classificação consulta $\times$ consulta, considerando o ranking criado com o resultado dos alinhamentos. 


\begin{tabular}{|c|c|c|c|c|c|}
\hline índice & top5 & classes & inter & mult & mult2 \\
\hline MRR & $93 \%$ & $91 \%$ & $91 \%$ & $93 \%$ & $94 \%$ \\
\hline Recall & $97 \%$ & $97 \%$ & $92 \%$ & $94 \%$ & $96 \%$ \\
\hline
\end{tabular}

Tabela 4.9: Valores gerais de $M R R$ e recall em função do modelo de ranking. 


\section{Capítulo 5}

\section{Conclusão}

Pelos experimentos apresentados pudemos ver que o Soundhound alcança resultados notáveis em uma ampla base de dados. Não foi possível reproduzir, no contexto da base de dados utilizada e das técnicas de representação e alinhamento estudadas, o mesmo desempenho dessa ferramenta comercial, mas em alguns cenários específicos observamos até mesmo resultados superiores aos do Soundhound. Observamos também que a separação dos aspectos melódicos da altura e do ritmo, embora sugerida por autores de trabalhos de QBH, pode não ser a melhor escolha ao considerarmos esquemas de representação alternativos, produzindo resultados sempre muito inferiores aos dos outros métodos.

Na tabela 5.1 vemos que no geral o experimento utilizando perfis de $F_{0}$ e comparando consultas cantaroladas com registros cantarolados por outros usuários obteve os melhores resultados para a maioria das melodias, apesar de se observar uma queda na performance nas melodias com poucas amostras na base de dados, produzindo resultados inferiores ao Soundhound em três melodias (2, 8 e 9$)$.

Na média geral destes resultados se confirma uma certa tendência, pois o desempenho médio do experimento usando perfis de $F_{0}$ foi maior do que o do Soundhound, e a variabilidade desses resultados (desvio padrão) foi consideravelmente menor com os perfis de $F_{0}$. Os resultados de quase todos os experimentos com o Soundhound são inferiores aos $90 \%$ esperados (as exceções foram as melodias 10, 30 e 37), e em apenas 13 das 29 melodias conhecidas pelo Soundhound o resultado dessa ferramenta foi igual ou superior a $80 \%$. Por outro lado, os perfis de $F_{0}$ produziram resultados acima de $90 \%$ para 18 das 29 melodias, ou acima de $80 \%$ para 25 dentre as 29 consideradas.

- O Soundhound possui um desempenho adequado para um certo número de consultas testadas, porém seu desempenho é muito variável, além de possuir uma aleatoriedade em buscas repetidas com a mesma consulta cantarolada, o que poderia ser tomado como um ponto negativo.

- A representação puramente melódica, apesar de computacionalmente muito eficiente, não produziu resultados satisfatórios. É complicado, a partir desse experimento, dizer que a dificuldade do algoritmo se deve exclusivamente à restrição de informação melódica, pois o resultado da transcrição nem sempre é correto, e isso tem um impacto grande nas respostas devolvidas. Essa observação indica a necessidade de experimentos futuros usando uma base de consultas transcritas manualmente (ou com transcrições automáticas corrigidas manualmente), a fim de estabelecer o potencial desse esquema de representação no contexto de QBH, de forma independente da qualidade dos algoritmos de transcrição.

- Os melhores resultados que encontramos usaram o algoritmo que alinha consultas cantaroladas com outras consultas cantaroladas. Porém, é difícil generalizar esses resultados em comparação com o Soundhound, pois essa ferramenta possui um banco de dados muito maior que o do nosso experimento.

Portanto, dentre as questões levantadas no início deste trabalho: o Soundhound retorna respostas razoáveis na maior parte do tempo; A representação melódica possui espaço a ser trabalhada, 


\begin{tabular}{|c|c|c|c|}
\hline Melodia & Soundhound & Perfis de $F_{0}$ & Sequências melódicas \\
\hline 1 & $21.05 \%$ & $87 \%$ & $10 \%$ \\
\hline 2 & $64.29 \%$ & $71 \%$ & $28 \%$ \\
\hline 7 & $86.67 \%$ & $86 \%$ & $40 \%$ \\
\hline 8 & $86.67 \%$ & $48 \%$ & $6 \%$ \\
\hline 9 & $60 \%$ & $58 \%$ & $50 \%$ \\
\hline 10 & $100 \%$ & $92 \%$ & $10 \%$ \\
\hline 11 & $58.33 \%$ & $89 \%$ & $20 \%$ \\
\hline 13 & $60 \%$ & $97 \%$ & $6 \%$ \\
\hline 14 & $80 \%$ & $89 \%$ & $45 \%$ \\
\hline 15 & $65 \%$ & $79 \%$ & $37 \%$ \\
\hline 17 & $45 \%$ & $88 \%$ & $22 \%$ \\
\hline 18 & $80 \%$ & $98 \%$ & $40 \%$ \\
\hline 20 & $65 \%$ & $97 \%$ & $21 \%$ \\
\hline 22 & $55 \%$ & $94 \%$ & $35 \%$ \\
\hline 23 & $60 \%$ & $92 \%$ & $9 \%$ \\
\hline 24 & $30 \%$ & $92 \%$ & $38 \%$ \\
\hline 26 & $70 \%$ & $91 \%$ & $57 \%$ \\
\hline 27 & $80 \%$ & $96 \%$ & $2 \%$ \\
\hline 29 & $80 \%$ & $97 \%$ & $38 \%$ \\
\hline 30 & $95 \%$ & $98 \%$ & $9 \%$ \\
\hline 33 & $50 \%$ & $90 \%$ & $6 \%$ \\
\hline 36 & $80 \%$ & $85 \%$ & $2 \%$ \\
\hline 37 & $95 \%$ & $90 \%$ & $21 \%$ \\
\hline 38 & $80 \%$ & $93 \%$ & $33 \%$ \\
\hline 41 & $80 \%$ & $99 \%$ & $5 \%$ \\
\hline 42 & $70 \%$ & $93 \%$ & $8 \%$ \\
\hline 43 & $23.33 \%$ & $92 \%$ & $6 \%$ \\
\hline 44 & $75 \%$ & $89 \%$ & $10 \%$ \\
\hline 45 & $60 \%$ & $95 \%$ & $5 \%$ \\
\hline Geral & $66.66 \%$ & $92.78 \%$ & $21.43 \%$ \\
\hline Desvio Padrão & $20.82 \%$ & $5.92 \%$ & $15.31 \%$ \\
\hline
\end{tabular}

Tabela 5.1: Lista geral de resultados agrupados por melodia

mas consegue retornar respostas corretas, apesar de não fazê-lo na maioria das vezes; A representação rítmica não conseguiu retornar resultados razoáveis no domínio utilizado neste trabalho; $\mathrm{O}$ algoritmo de transcrição influencia os resultados, mas dentre as ferramentas analisadas os melhores resultados ficaram próximos; O algoritmo de consultas contra consultas conseguiu chegar próximo dos resultados obtidos na ferramenta existente e obteve respostas corretas na maior parte dos casos analisados.

Concluindo, os dados deste trabalho sugerem que utilizar transcrição para uma representação simbólica compacta pode prejudicar a performance de alinhamento para consultas cantaroladas, mas é um modelo com uma grande vantagem em tempo de processamento. Utilizar uma estratégia de alinhamento de perfis de $F_{0}$ entre registros cantarolados parece um bom caminho, mas ainda parece ser necessário um esforço de pesquisa para diminuir a quantidade de tempo de processamento necessário, especialmente em contextos de larga escala (no processamento em lote ou em serviços com grande número de usuários). 


\section{Referências Bibliográficas}

Barlow e Morgenstern(1966) Harold Barlow e Sam Morgenstern. A dictionary of opera and song themes, including cantatas, oratorios, lieder, and art songs. Crown Publishers. Citado na pág. 21

Barlow e Morgenstern(1975) Harold Barlow e Sam Morgenstern. A dictionary of musical themes. Crown Pub. Citado na pág. 21

Collins(2010) Nick Collins. Introduction to Computer Music. John Wiley Sons. ISBN 0470714557 , 9780470714553. Citado na pág. 5

Costa(2015) Maurício do Vale Madeira da Costa. Sistema de consulta cantarolada com geração automática de um banco de músicas adaptativo, 2015. Citado na pág. 2

Dannenberg et al.(2007) Roger B. Dannenberg, William P. Birmingham, Bryan Pardo, Ning Hu, Colin Meek e George Tzanetakis. A comparative evaluation of search techniques for query-byhumming using the musart testbed. Journal of the American Society of Information Science Technololgy, páginas 687-701. Citado na pág. 19, 21

Ellis et al.(2011) Daniel P. W. Ellis, Brian Whitman e Alastair Porter. Echoprint: An open music identification service. Columbia University. doi: 10.7916/d8w09g8w. URL https: //academiccommons.columbia.edu/doi/10.7916/D8W09G8W. Citado na pág. 1

Goródscy(2019) Fábio Goródscy. Códigos e experimentos da dissertação de mestrado intitulada "Estratégias de alinhamento para consulta cantarolada", 2019. URL https://github.com/ fabiogoro/qbh. Acessado em 30/08/2019. Citado na pág. 23, 28

Kotsifakos et al.(2011) Alexios Kotsifakos, Panagiotis Papapetrou, Jaakko Hollmen e Dimitrios Gunopulos. A subsequence matching with gaps-range-tolerances framework: A query-byhumming application. Em Proceedings of the VLDB Endowment. Citado na pág. 2, 11, 14, 16, 21, 27

Kotsifakos et al.(2012) Alexios Kotsifakos, Panagiotis Papapetrou, Jaakko Hollmen, Dimitrios Gunopulos, Vassilis Athitsos e George Kollios. Hum-a-song: A subsequence matching with gapsrange-tolerances query-by-humming system. Em Proceedings of the VLDB Endowment, volume 5. Citado na pág. 2

López et al.(2004) Ernesto López, Martín Rocamora e Gonzalo Sosa. Búsqueda de música por tarareo, 2004. Proyecto de fin de carrera, Instituto de Ingenieria Eléctrica, Facultad de Ingenieria, Universidad de la República Oriental del Uruguay. Citado na pág. 2, 21

Maier(1978) David Maier. The complexity of some problems on subsequences and supersequences. Journal of the Association for Computing Machinery. Citado na pág. 11

MIREX(2017) MIREX. Music Information Retrieval EXchange competition on Query by Singing/Humming, 2017. URL https://www.music-ir.org/mirex/wiki/2017:Query_by_Singing/ Humming. Citado na pág. 2, 23 
Mitre e Queiroz(2005) Adriano Mitre e Marcelo Queiroz. Um sistema automático de transcrição melódica. Em Proceedings of the Brazilian Symposium on Computer Music. Citado na pág. 8, 27, 28

Moore(1990) Richard Moore. Elements of Computer Music. Prentice Hall. ISBN 0132525526, 9780132525527. Citado na pág. 5

Müller(2015) Meinard Müller. Fundamentals of Music Processing: Audio, Analysis, Algorithms, Applications. Springer Publishing Company, Incorporated, 1st edição. ISBN 3319219448, 9783319219448. Citado na pág. 5, 14

Roads et al.(1996) Curtis Roads, John Strawn, Curtis Abbott, John Gordon e Philip Greenspun. The Computer Music Tutorial. MIT Press, Cambridge, MA, USA. ISBN 0-252-18158-3. Citado na pág. 5

Salamon e Gómez(2012) Justin Salamon e Emilia Gómez. Melody extraction from polyphonic music signals using pitch contour characteristics. Em IEEE TRANSACTIONS ON AUDIO, SPEECH, AND LANGUAGE PROCESSING. Citado na pág. 8, 27, 28

Salamon et al.(2013a) Justin Salamon, Emilia Gómez, Daniel P. W. Ellis e Gael Richard. Melody extraction from polyphonic music signals: Approaches, applications and challenges. IEEE Signal Processing Magazine. Citado na pág. 22

Salamon et al.(2013b) Justin Salamon, Joan Serrà e Emilia Gómez. Tonal representations for music retrieval: from version identification to query-by-humming. Int. J. of Multimedia Info. Retrieval, special issue on Hybrid Music Info. Retrieval, 2(1):45-58. ISSN 2192-6611. doi: 10.1007/s13735-012-0026-0. URL http://dx.doi.org/10.1007/s13735-012-0026-0. Citado na pág. ix, 2

Serrà et al.(2009) Joan Serrà, Xavier Serra e Ralph G. Andrzejak. Cross recurrence quantification for cover song identification. New Journal of Physics, 11(9):093017. doi: 10.1088/1367-2630/11/ 9/093017. URL https://doi.org/10.1088/1367-2630/11/9/093017. Citado na pág. 2

Stasiak(2014) Bartłomiej Stasiak. Follow that tune - adaptive approach to dtw-based query-byhumming system. ARCHIVES OF ACOUSTICS, 39(4):467-476. Citado na pág. 2, 22

Wang(2003) Avery Wang. An industrial-strength audio search algorithm. Em Proceedings of the 4th International Conference on Music Information Retrieval. Citado na pág. 1

White(1978) George M. White. Dynamic programming, the Viterbi algorithm, and low-cost speech recognition. Em Proceedings of the 1978 IEEE International Conference on Acoustics, Speech, and Signal Processing. Citado na pág. 11

Wikipedia(2019) Wikipedia. Soundhound, 2019. URL https://en.wikipedia.org/wiki/ SoundHound. Citado na pág. 2 